\title{
The ABC7 regimen: a new approach to metastatic breast cancer using seven common drugs to inhibit epithelial-to-mesenchymal transition and augment capecitabine efficacy
}

This article was published in the following Dove Press journal:

Breast Cancer - Targets and Therapy

II July 2017

Number of times this article has been viewed

\author{
Richard E Kast ${ }^{1}$ \\ Nicolas Skuli ${ }^{2}$ \\ Samuel $\operatorname{Cos}^{3}$ \\ Georg Karpel-Massler ${ }^{4}$ \\ Yusuke Shiozawa ${ }^{5}$ \\ Ran Goshen ${ }^{6}$ \\ Marc-Eric Halatsch ${ }^{4}$ \\ 'IIAIGC Study Center, Burlington, VT, \\ USA; ${ }^{2}$ INSERM, Centre de Recherches \\ en Cancérologie de Toulouse - CRCT, \\ UMR 1037 Inserm/Université Toulouse \\ III - Paul Sabatier, Toulouse, France; \\ ${ }^{3}$ Department of Physiology and \\ Pharmacology, School of Medicine, \\ University of Cantabria and Valdecilla \\ Research Institute (IDIVAL), \\ Santander, Spain; ${ }^{4}$ Department \\ of Neurosurgery, Ulm University \\ Hospital, Ulm, Germany; ${ }^{5}$ Department \\ of Cancer Biology, Comprehensive \\ Cancer Center, Wake Forest School \\ of Medicine, Winston-Salem, NC, USA; \\ ${ }^{6}$ Eliaso Consulting Ltd., Tel Aviv-Yafo, \\ Israel
}

\begin{abstract}
Breast cancer metastatic to bone has a poor prognosis despite recent advances in our understanding of the biology of both bone and breast cancer. This article presents a new approach, the ABC7 regimen (Adjuvant for Breast Cancer treatment using seven repurposed drugs), to metastatic breast cancer. $\mathrm{ABC} 7$ aims to defeat aspects of epithelial-to-mesenchymal transition (EMT) that lead to dissemination of breast cancer to bone. As add-on to current standard treatment with capecitabine, $\mathrm{ABC} 7$ uses ancillary attributes of seven already-marketed noncancer treatment drugs to stop both the natural EMT process inherent to breast cancer and the added EMT occurring as a response to current treatment modalities. Chemotherapy, radiation, and surgery provoke EMT in cancer generally and in breast cancer specifically. ABC7 uses standard doses of capecitabine as used in treating breast cancer today. In addition, $\mathrm{ABC} 7 \mathrm{uses}$ 1) an older psychiatric drug, quetiapine, to block RANK signaling; 2) pirfenidone, an anti-fibrosis drug to block TGF-beta signaling; 3) rifabutin, an antibiotic to block beta-catenin signaling; 4) metformin, a first-line antidiabetic drug to stimulate AMPK and inhibit mammalian target of rapamycin, (mTOR); 5) propranolol, a beta-blocker to block beta-adrenergic signaling; 6) agomelatine, a melatonergic antidepressant to stimulate M1 and M2 melatonergic receptors; and 7) ribavirin, an antiviral drug to prevent eIF4E phosphorylation. All these block the signaling pathways - RANK, TGF-beta, mTOR, beta-adrenergic receptors, and phosphorylated eIF4E that have been shown to trigger EMT and enhance breast cancer growth and so are worthwhile targets to inhibit. Agonism at MT1 and MT2 melatonergic receptors has been shown to inhibit both breast cancer EMT and growth. This ensemble was designed to be safe and augment capecitabine efficacy. Given the expected outcome of metastatic breast cancer as it stands today, $\mathrm{ABC} 7$ warrants a cautious trial.
\end{abstract}

Keywords: ABC7, breast cancer, agomelatine, capecitabine, metformin, pirfenidone, propranolol, quetiapine, repurposing, ribavirin, rifabutin, TGF-beta

\section{Plain language summary}

This article presents the rationale and thinking behind the $\mathrm{ABC} 7$ regimen for metastatic breast cancer. Since there is currently no cure for breast cancer once it has spread to bone and other organs beyond the breast itself, the ABC7 regimen was designed to take advantage of ancillary attributes of seven common and readily available noncancer treatment drugs that, in theory, should make current traditional cytotoxic chemotherapy with capecitabine more effective. The $\mathrm{ABC} 7$ regimen has not been shown to be safe or effective yet. In the current article, we discuss an untested proposal for a new treatment approach to metastatic breast cancer.
Correspondence: Richard E Kast IIAIGC Study Center, 22 Church Street, Burlington, VT 0540I, USA

Tel +l 8025577278

Email richarderickast@gmail.com 


\section{Introduction}

Estrogen-positive metastatic breast cancer cannot be cured currently. ${ }^{1}$ One major metastatic site of breast cancer is bone. Once breast cancer metastasizes to bone, the survival rate declines despite recent advances in local treatments of breast cancer. Current treatment strategies for bone metastasis, including bone-targeted agents (bisphosphonate and denosumab), provide only palliation. New and effective therapeutic strategies for this still incurable disease are therefore urgently needed.

This article reviews the attributes of seven currently marketed drugs that, as indicated by prior research data, will block or partially block the escape pathways from current traditional treatments. The seven drugs of $\mathrm{ABC} 7$ were chosen by first identifying the basic pathways by which EMT is initiated and maintained. We then reviewed 1000 of the most commonly used drugs $^{2}$ for which we have both usual plasma levels and published data showing potential inhibitory interaction with these pathways. The resulting list was reduced by semi-subjective evaluation of the strength of data on their EMT inhibition benefit versus the drugs' expected tolerability. The better the tolerability, the weaker the data had to be for inclusion.

This $\mathrm{ABC} 7$ regimen is designed to block several core breast cancer growth signals in a coordinated manner, thereby augmenting the cytotoxicity of a currently used cytotoxic chemotherapy drug, capecitabine. Figure 1 shows an overview schematic of the biochemistry that $\mathrm{ABC} 7$ is designed to influence. This is explained in detail in the respective drug discussions in the "Drugs to inhibit EMT" section. Table 1 gives an overview of the $\mathrm{ABC} 7$ drugs and their intended targets in treating breast cancer.

The ABC7 regimen follows the approach of previous cancer treatment regimens, for example, MTZ regimen, ${ }^{3}$ COMBAT regimen, ${ }^{4}$ MEMMAT regimen, a current trial of Peyrl et al's seven-drug cocktail (ClinicalTrials.gov Identifier: NCT01356290), and CUSP9 regimen. ${ }^{5,6}$ In all of the studies, extensive use is made of drugs not primarily marketed to treat cancer but that have ancillary attributes that research data indicate would enhance the anticancer effect of a cytotoxic, traditional cancer treatment drug. The ancillary drugs exert anticancer effects by blocking various growth-enhancing survival pathways used by the target cancer or as for agomelatine are agonists at growth-retarding receptors.

Similar to other cancers, breast cancer has heterogeneous regions within the same tumor - different areas that depend on or use different growth-signaling pathways. This is related to but distinct from the idea of clonal evolution driven by cytotoxic chemotherapy selection. Both forms of heterogeneity exist in a typical breast cancer, proteomic and genomic. $\mathrm{ABC} 7$ aims to inhibit breast cancer by pharmacological manipulation of what genes are expressed and what genes are not, as well as by targeting different clonal variants of the original breast cancer clone.

Because of these limitations, we do not expect testing for molecular markers to be predictive or useful. In addition, further intensifying the spatial and temporal diversity of the molecular status, particularly for EMT markers, are the diversity-driving effects of chemotherapy ${ }^{7}$ and discussed in greater detail in the following sections.

Cytotoxic chemotherapy also induces important receptor status changes in a large minority of breast cancer cases. ${ }^{8,9}$ Typical findings are as follows: $13 \%$ changed from $\mathrm{HR}+$ to $\mathrm{HR}-, 5 \%$ changed from $\mathrm{HR}-$ to $\mathrm{HR}+, 6 \%$ changed from HER $2+$ to HER2, 3\% changed from HER2 to HER2+, and $13 \%$ changed to triple negative. ${ }^{8}$

Multiple signaling systems have been identified that drive metastatic breast cancer. ${ }^{1,9-11}$ These growth-driving receptors can cross cover for each other. ${ }^{1,9-11}$ When one is pharmacologically blocked, several parallel growth-driving pathways can become active, taking the place of the blocked pathways. Growth factor signaling converges from a wide variety of outer membrane receptors to more restricted, fewer, intracellular pathways. This is, more elegantly stated, the spatial-temporal genomic and proteomic range, the "genetic collectives [that] dominate the landscape of advanced-stage (malignant) disease." ${ }^{11,12}$ We see this as mandating an integrated, coordinated polypharmacy to successfully address these malignancy attributes.

Capecitabine is intracellularly metabolized to 5-FU; the details are given in the "Capecitabine: $359 \mathrm{Da}$, half-life $<1$ hour" section. $\mathrm{ABC} 7$ drugs are designed to make 5-FU more effective.

The results of several recent ER+ metastatic breast cancer studies are listed in Table 2. These studies cannot be judged simply by overall survival in that entry requirements were different, with different kinds and number of prior treatments. These numbers in Table 2 are for general idea only. ${ }^{1}$ One cannot conclude that one of these is better than another.

In general, post-progression survival durations in recent Phase III studies of combination therapy ranged from approximately 16 to 33 months. ${ }^{1}$

EMT is a feature of cancers generally ${ }^{13}$ and breast cancer specifically. ${ }^{14,15}$

Table 3 lists several features and behaviors associated with the two (epithelial and mesenchymal) states. Interestingly, a transcription factor ZEB1, known to control EMT, 


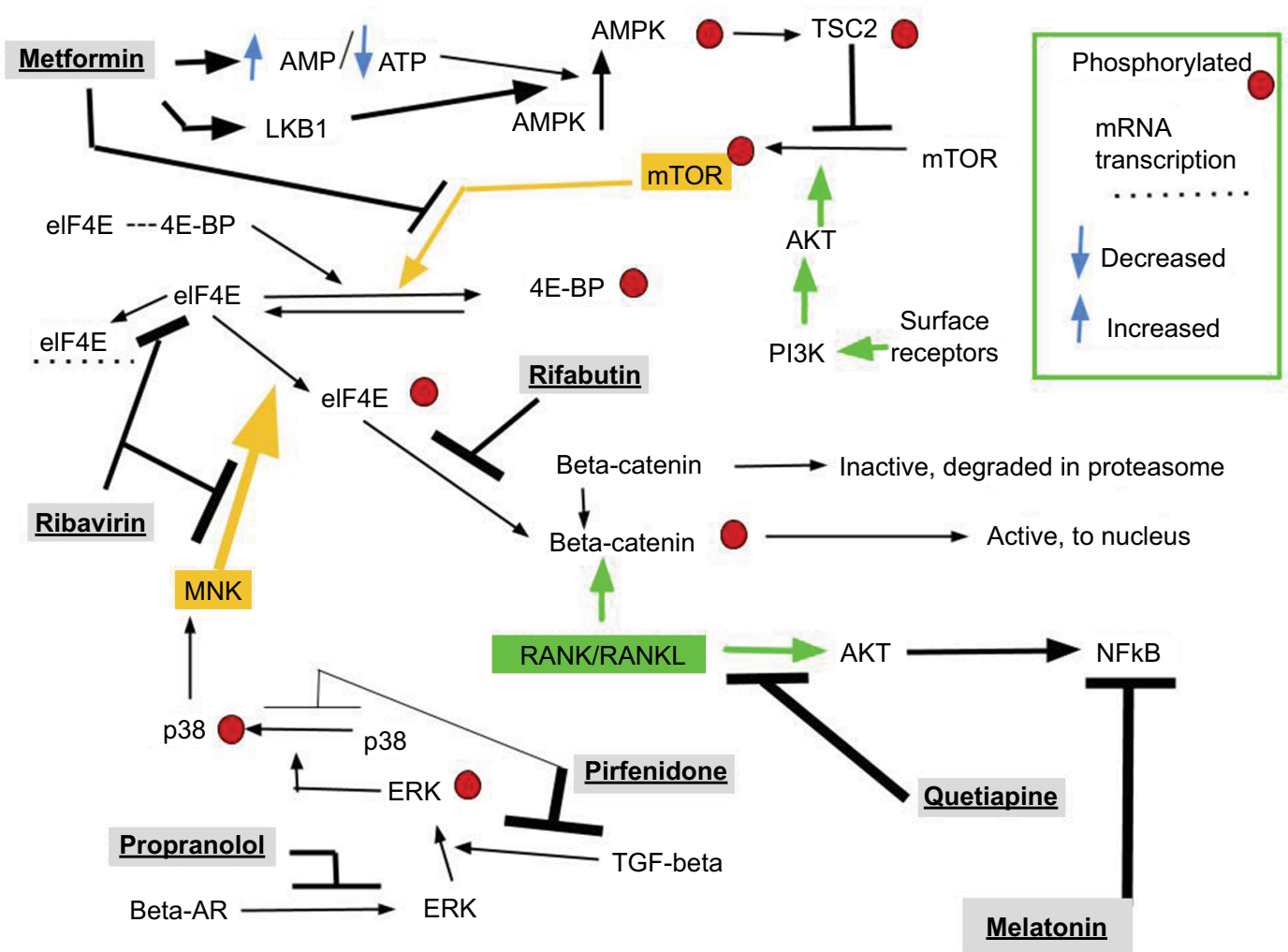

Figure I The basic biochemical, intracellular, and receptor pathways relating to interventions of the ABC7 regimen for advanced breast cancer.

Notes: This is the basic breast cancer intracellular circuitry that the ABC7 regimen attempts to address. The two major controllers or stimuli for elF4E activation are indicated by yellow arrows, the p-mTOR and the MNK paths.

Table I The drugs of $A B C 7$, their targets during treatment of breast cancer, and suggested doses

\begin{tabular}{llll}
\hline Drug & Target in breast cancer treatment & Starting dose & Target dose \\
\hline Capecitabine & DNA synthesis & $600 \mathrm{mg} / \mathrm{m}^{2}$ twice daily. & $1250 \mathrm{mg} / \mathrm{m}^{2}$ twice daily. 7 days on, 7 days off or I4 days on, \\
& & 7 days on, 7 days off & 7 off \\
Quetiapine & RANK/RANKL & $50 \mathrm{mg}$ once at bedtime & $300-600 \mathrm{mg}$ once at bedtime \\
Pirfenidone & TGF-beta & $200 \mathrm{mg}$ three times daily & $600 \mathrm{mg}$ three times daily \\
Rifabutin & BCL-6; beta-catenin & $150 \mathrm{mg} /$ day & $300 \mathrm{mg} /$ day \\
Metformin & AMPK*; mTOR; mitochondria oxphos & $500 \mathrm{mg}$ once daily & $1000 \mathrm{mg}$ twice daily \\
Propranolol & Beta-adrenergic receptors & $10 \mathrm{mg}$ twice daily & Uptitrate as tolerated \\
Agomelatine & Melatonergic receptors* & $25 \mathrm{mg}$ once at bedtime & $50 \mathrm{mg}$ once at bedtime \\
Ribavirin** & elF4E; MNK; IMPDH & $600 \mathrm{mg} /$ day & $1200 \mathrm{mg} /$ day \\
\hline
\end{tabular}

Notes: The drugs are listed in a suggested order of addition. Pace of drug addition is individualized per patient and physician estimations of risk/benefit. *Note that all entries denote inhibition of named target except for metformin that activates AMPK and agomelatine that stimulates melatonin receptors. All drugs, except capecitabine, are given continuously without interruption. Capecitabine is given on 7 days on, 7 days off, or 14 days on, 7 days off cycles. **Ribavirin is likely to give unpleasant side effects and depressed mood-but is potentially a beneficial enough drug to try.

Table 2 Representative recent trials in metastatic HR+ breast cancer

\begin{tabular}{lll}
\hline Intervention & Months survival & Trial \\
\hline Anastrozole + fulvestrant & 48 & SWOG \\
Anastrozole + fulvestrant & 38 & FACT \\
Anastrozole + fulvestrant & 21 & SoFEA \\
Letrozole + fulvestrant & 52 & LEA \\
Everolimus + exemestane & 31 & BOLERO 2 \\
\hline
\end{tabular}

contributes to breast cancer osteolytic bone metastasis, but not brain or lung metastasis. ${ }^{16,17}$
EMT is a phase transition, where flat, sessile, mutually adherent epithelioid cells take on a rounded, non-adherent, motile mesenchymal shape and behavior. ${ }^{18-20}$ The reverseless transient state and process, MET, also occurs and is also a feature of robust or aggressive cancer growth. ${ }^{21}$ Post-EMT cells tend to be invasive but proliferation restricted. Post-MET cells tend to be proliferative but have limited invasiveness. ${ }^{18-20}$ Breast cancers develop in proximity to adipose tissue. Adipocytes are a further trigger to EMT. ${ }^{22}$ The relationship between stem cell subpopulations within a cancer and EMT 
process is also unclear, ${ }^{23}$ and the two populations probably largely overlap.

Perhaps our deepest insight into the EMT process in breast cancer came from a study by Bulfoni et al. ${ }^{24}$ They showed that all patients with metastatic breast cancer had CTCs. These circulating cancer cells split into four groups: those with epithelial, those with mesenchymal, those with both, and those with neither marker. Patients with higher numbers of circulating cancer cells that expressed both markers had shorter overall survival.

Survival as a function of E-cadherin expression, representative of epithelial state, and fibronectin, representative of mesenchymal state, was examined by immunohistochemistry on 1495 breast cancer biopsies. ${ }^{25}$ More E-cadherin and less fibronectin are associated with longer survival. ${ }^{25}$ Breast cancer patients whose tissue expresses greater EMT-related protein have shorter survival. ${ }^{26}$ EMT drives chemotherapy resistance and other poor prognosis features in breast cancer. ${ }^{27-29}$ In addition, a greater degree of metabolic changes characteristic of EMT in breast cancer predicts shorter overall survival. ${ }^{30}$

Medical research discusses vimentin, fibronectin, and $\mathrm{N}$-cadherin as markers of EMT process, but these proteins would be more accurately viewed as mediators of the attributes we designate EMT.

As indicated in Table 3, fibronectin is a characteristic marker of EMT. Higher breast cancer tissue expression of fibronectin correlates with shorter survival. ${ }^{31,32}$ A range of other characteristic behavioral and morphological attributes of EMT and MET states is also outlined in Table 3.

Table 3 Characteristic protein markers and mediators of EMT in breast cancer

\begin{tabular}{lll}
\hline Marker & Epithelial state & Mesenchymal state \\
\hline E-cadherin & Increased & Decreased \\
N-cadherin & Decreased & Increased \\
ZO-I & Increased & Decreased \\
Occludin & Increased & Decreased \\
Vimentin & Decreased & Increased \\
Fibronectin & Decreased & Increased \\
MMP-2 & Decreased & Increased \\
MMP-9 & Decreased & Increased \\
Phenotype & Epithelial state & Mesenchymal state \\
Motility & Sessile & Motile \\
Shape & Elongated & Rounded \\
Adherence & Adherent to neighbors & Non-adherent to neighbors \\
Invasion & Noninvasive & Invasive \\
Proliferation & Higher proliferation & Lower proliferation \\
Microtentacles & Absent & Present \\
\hline
\end{tabular}

Abbreviation: EMT, epithelial-to-mesenchymal transition.

\section{Chemotherapy triggers EMT}

Paclitaxel triggers EMT in breast cancer, increasing mesenchymal markers, vimentin and fibronectin, and decreasing epithelial marker, ZO-1. ${ }^{33}$ Experimental inhibitors of TGFbeta signaling block paclitaxel-induced EMT and suppress paclitaxel-induced CSC properties. ${ }^{33}$ Paclitaxel also increases EMT markers in mouse breast cancer cell line, MCF-7/PAX. ${ }^{34}$ Doxorubicin exposure enhances gastric cancer's EMT marker expression..$^{35}$

These reports, combined with similar findings in other cancers, allow a general statement of a core principle of oncology: cytotoxic chemotherapies tend to provoke EMT. Such a conjecture is amply supported by the recent work of Yoshimasu et $\mathrm{al}^{36}$ who reported that cisplatin, 5-FU, gemcitabine, paclitaxel, and vinorelbine show hormesis when tested individually.

\section{Surgical trauma or fine-needle biopsy triggers EMT}

Of concern in current medical practice, there is a tendency for cancers generally, and breast cancer specifically, to be triggered by any kind of tissue disruption - including fineneedle biopsy - to undergo EMT with consequent cancer cell shedding to circulation. Such hematogenous tumor cell dissemination could be the origin of later overt metastases.

Breast cancers in mice release a flood of CTCs after simple fine-needle biopsy. ${ }^{37}$ Clinical needle biopsy of breast cancer triggers recruitment of inflammatory cells to the biopsy site and causes increased tumor cell mitoses in the biopsied area. ${ }^{38}$ In a second murine breast cancer study, both fineneedle biopsy and surgical resection resulted in the release of a flood of CTCs, but noteworthy in this work is that biopsy resulted in greater and longer lasting appearance of circulating cancer cells than did surgical resection. ${ }^{39}$ These murine data were replicated by Kaigorodova et $\mathrm{a}^{40}$ who showed that simple fine-needle biopsy of human breast cancers releases a flood of breast cancer cells into the general circulation. These authors found that although some released CTCs had CSC markers and attributes and some did not, none of them had the particular EMT markers for which they were tested.

This worrisome situation in breast cancer is similar to data collected in other cancers. For example, treatment with radioactive needle insertion into prostate cancer results in significant hematological shedding of tumor cells post procedure. ${ }^{41}$ Standard transrectal ultrasound-guided prostate needle biopsy results in detectable prostate cancer cells in the circulation in half of patients. ${ }^{42}$ Oral squamous cell carcinoma biopsies result in $16 \%$ of patients having post-biopsy 
CTCs. ${ }^{43}$ Simple wide excision that does not disrupt the tumor tissue integrity did not result in postoperative CTCs, whereas incisional biopsy did. ${ }^{44}$

A study is therefore required comparing the long-term outcome potential difference between those having fineneedle biopsy versus those having initial wide lesion excision. If initial excision that leaves the suspicious mass intact does result in fewer later disseminated metastases, it might be worth the iatrogenic morbidity incurred by the consequent excision of some benign masses.

\section{Radiation triggers EMT}

Above we reviewed some evidence that chemotherapy and mechanical tissue disruption give rise to CTC and EMT in surviving cells. Below we review data showing radiation causes CTC and EMT as well. ${ }^{45,46}$ For a few specific examples, as in other cancers, ${ }^{47}$ breast cancers synthesize GM-CSF that then functions as a growth factor for them. ${ }^{48}$ Clinically used, radiation treatment not only kills breast cancer cells and prolongs survival in breast cancer but also triggers exposed residual cells that are not killed to undergo EMT, to start migrating, and to synthesize increased amounts of autocrine growth factor, GM-CSF. ${ }^{49}$ Radiation also increases IL-6, migration, and EMT markers in murine and human breast cancer cell lines. ${ }^{50}$ The subject of radiation-induced EMT and radiation-induced increase in CTCs was recently reviewed by Lee et al. ${ }^{51}$

Clinically, finding greater post-EMT CTCs confers a worse prognosis with more aggressive disease course and greater metastatic proclivity in colon cancer ${ }^{52}$ and finding circulating clusters of vimentin-positive gastric cancer cells confers a worse prognosis ${ }^{53}$ as did finding circulating cancer cell clusters and vimentin-positive CTC in colon cancer. ${ }^{54}$ Surgery for epithelial ovarian cancer causes an increase in both EMT-positive and EMT-negative CTCs, but there is a disproportionate increase in EMT positive. The increase in EMT-positive CTCs was even stronger after platinum-based chemotherapy. ${ }^{7}$ As Kolbl et $\mathrm{al}^{55}$ point out, EMT precedes the release of CTCs but after entering circulation CTC can revert to epithelial or partial epithelial phenotype.

Based on all these evidences, it seems that inhibiting EMT is a worthwhile goal during breast cancer treatment and that current common cancer treatments have elements of cancer growth stimulation inherent to them, or as Niccolo Machiavelli (born 1469-died 1527) said in 1513:

People should either be caressed or crushed. If you do them minor damage they will get their revenge; but if you cripple them there is nothing they can do. If you need to injure someone, do it in such a way that you do not have to fear their vengeance.

ABC7 regimen was crafted with that in mind.

\section{Drugs to inhibit EMT Quetiapine: $384 \mathrm{Da}$, cyp3A4 to norquetiapine, 6-hour half-life}

The RANK, its ligand (RANKL), and the soluble decoy receptor OPG (or bone protector) are central elements in breast cancer's establishment of metastases to bone. ${ }^{56}$ Early indications are that quetiapine inhibits the RANK/RANKL signaling system. ${ }^{57}$

Several forms of pro-RANKL are expressed on osteoblasts. After proteolytic release, RANKL binds to RANK leading to osteoclast syncytium formation then osteoclasts' resorption of bone. Osteopetrosis results when RANK/ RANKL system is nonfunctional. RANK/RANKL also functions in guiding normal breast gland ontogeny. There occurs an ebb and flow of RANK expression in mammary duct epithelial cells during the menstrual cycle, the increase occurring in late luteal phase. RANK/RANKL function is essential to the luminal epithelial proliferation seen particularly where ducts branch. ${ }^{56}$ Higher levels of RANK/RANKL in human breast cancer biopsy tissue correlate with higher metastasis likelihood and shorter survival. ${ }^{58}$

PR-negative cells are affected through RANKL-induced paracrine actions leading to proliferation of mammary epithelial PR-negative cells. ${ }^{59}$

RANK/RANKL is a core physiologic signaling system allowing circulating breast cancer cells to metastasize to bone. ${ }^{60,61}$ RANK/RANKL is a principal part of the complex signaling giving rise to breast cancer's propensity to metastasize to bone.

Since breast cancer commonly metastasizes to bone with consequent bone pain, pathological fractures, vertebrae compressions, and hypercalcemia, this process is important to block. Breast cancer cells are continuously shed into circulation from the primary and metastatic sites. Why then do these CTCs choose to establish growth preferentially in bone? This is because these CTCs can establish growth-enhancing communication with bone cells, specifically osteoblasts, and they do so primarily via RANK/RANKL. ${ }^{62}$ Muscle, skin, liver, spleen, fat, and other sites of less common breast cancer metastasis cannot so reciprocally communicate.

Osteoblasts receiving RANKL signaling transform to syncytial osteoclasts that resorb bone and increase TGF-beta. TGF-beta is also stored in bone, then released with any bone 
dissolution. This creates room for the CTCs to grow and free TGF-beta signaling prompting them to do so, ${ }^{62,63}$ making the TGF-beta blocking drug pirfenidone, which is discussed in the following sections, an ideal partner drug for quetiapine during metastatic breast cancer treatment.

An initial dose can be $50 \mathrm{mg}$ once at bedtime, uptitrating to a target dose of quetiapine $300 \mathrm{mg}$ or more as tolerated, given once at bedtime. Tiredness for a few hours on awakening is common upon starting quetiapine. It then abates after a week or so but reappears after each dose increase. Some weight increase due to increased appetite can be expected. Otherwise, side effects are not common.

\section{Pirfenidone: I85 Da, cyp IA2, 3-hour half-life}

Pirfenidone is a 185 Da drug approved and marketed to treat idiopathic pulmonary fibrosis. ${ }^{64}$ Mild-to-moderate, reversible, nausea, dyspepsia, and rash are side effects in about one-third of treated patients, but these often resolve with continued use. Approximately $2403 \mathrm{mg} /$ day divided into three equal doses is a common pirfenidone dose in treating its marketed indication, idiopathic pulmonary fibrosis. ${ }^{64,65}$

Pirfenidone blocks TGF-beta signaling. ${ }^{66-70}$ TGF-beta is a $25 \mathrm{kDa}$ signaling protein proteolytically clipped from a larger precursor protein. Carboplatin induces elevation of TGF-beta and triggers EMT in NSCLC, as given in the "Chemotherapy triggers EMT" section, ${ }^{71}$ both effects blocked by coadministration with pirfenidone. ${ }^{71}$

TGF-beta signaling is a major driver of EMT in cancer generally ${ }^{72-74}$ and in breast cancer EMT specifically. ${ }^{75-78}$ TGFbeta is a facilitating element of many cancers by promoting angiogenesis and differentiation, by immune suppression, by promoting loss of cell-to-cell contact, and particularly by promoting EMT. Pirfenidone inhibits TGF-beta-induced phosphorylation of SMAD3, p38, and AKT. TGF-beta provides a "get up and go" signal for breast cancer. ${ }^{79}$ In a murine breast cancer model, TGF-beta exposure also enhances normal lung's ability to better support establishment of breast cancer metastases. ${ }^{80}$ TGF-beta drives breast cancer's EMT and various biochemical, morphological, and behavioral changes characteristic of EMT. ${ }^{10,81-83}$ The manifold paths by which TGF-beta signaling leads to or enhances EMT specifically in breast cancer were outlined by Tan et al, ${ }^{18} \mathrm{Chen}$ et al, ${ }^{81}$ Nooshinfar et al, ${ }^{84}$ and Felipe Lima et al. ${ }^{75}$

TGF-beta dependency for taking on typical mesenchymal morphology, increased motility, and increased vimentin expression after radiation exposure was shown in breast, colon, and lung adenocarcinoma cell lines. ${ }^{85}$
Preclinical studies have shown activity in pirfenidone's enhancing cisplatin cytotoxicity to NSCLCs. ${ }^{86}$ In addition, pirfenidone enhances radiation and sunitinib cytotoxicity in Lewis lung cancer cells ${ }^{87}$ and reduces desmoplasia in pancreatic cancer. ${ }^{88}$ Growth of human TNBC tissue (ER negative, PR negative, HER 2 negative) xenografted to nude mice was inhibited more by pirfenidone and doxorubicin than by doxorubicin alone. ${ }^{89}$ In another murine breast cancer model, pirfenidone reduced intratumoral collagen and hyaluronan by TGF-beta inhibition with consequent improvement of doxorubicin efficacy. ${ }^{90}$

Pirfenidone disrupts Hh signaling in parallel with TGFbeta inhibition, a worthwhile added benefit during breast cancer treatment. ${ }^{91}$

The starting dose of pirfenidone is $267 \mathrm{mg}$ three times a day. This is gradually increased at 14-day intervals as tolerated to $801 \mathrm{mg}$ three times daily. Pirfenidone at $400 \mathrm{mg}$ three times daily (1200 mg/day) used to treat potential progression of hepatitis C-related fibrosis reduced circulating TGF-beta and IL-6. ${ }^{92}$ Abdominal pain, rash, and nausea were seen in a half of treated patients, but these side effects tended to subside within a month or two and no patient dropped out due to them.

\section{Ribavirin: $244 \mathrm{Da}$, 6-day half-life for a single oral dose, up to 12 days after continuous use}

Since its introduction to clinical practice in the late 1970s, ribavirin had been used to treat various viral infections, later becoming central to a now-outmoded hepatitis $\mathrm{C}$ treatment. Ribavirin remains useful in treating human respiratory syncytial virus infections and selected other rarer virus infections such as those of the hantavirus group. ${ }^{93}$ Ribavirin is currently being investigated in numerous clinical trials for its therapeutic activity in various cancers, particularly acute myeloid leukemia (NCT02109744, NCT02073838), head and neck cancer (NCT01268579), and notably for ABC7, metastatic breast cancer (NCT01056757).

Although ribavirin's mechanisms of antiviral and anticancer action are uncertain and probably will vary between viruses, several potential mechanisms of action have been identified. One proposes that ribavirin enters the cell via a nucleoside transport mechanism, intermingling itself within the viral RNA, thus inhibiting/altering viral RNA synthesis. However, ribavirin, particularly when paired with interferonalpha, activates anti-inflammatory responses in various other ways. Alternatively, due to the fact that ribavirin is structurally analogous to GTP, a purine nucleoside, ribavirin can be incorporated into the cell passively, thereafter competitively 
binding to, and inhibiting, RNA polymerase, and RNA synthesis as a whole; ribavirin often achieves this via blocking the IMPDH pathway, among other pathways such as the eIF4E pathway. Ultimately, five major mechanisms of action have been proposed: ${ }^{94-96}$

1. Immunostimulation by upregulating cytokines to shift Th1/2 cell balance to Th1 dominance.

2. Inhibition of $24 \mathrm{kDa}$ eIF4E function, thereby inhibiting mRNA capping and translation initiation.

3. Modulation of interferon-alpha-related gene expression.

4. Direct inhibition of IMPDH with consequent depletion of intracellular GTP.

5. After triphosphorylation, ribavirin triphosphate is incorporated into replicating RNA viral RNA polymerases with consequent induction of viral mutagenesis.

How ribavirin acts vis-a-vis eIF4E is as follows:

eIF4E forms part of the multimeric cap-dependent mRNA translation initiation complex. Mammalian cap-dependent translation starts with that complex binding to an RNA methyl-nucleotide. eIF4E has many positive and negative control points, two of which are 1) posttranslational phosphorylation and 2) 4E-BPs. ${ }^{97-99}$ There are several variants of 4E-BP protein, hereafter designated simply as 4E-BP. 4E-BP is in turn controlled by its phosphorylation status.

eIF4E non-covalently bound to $4 \mathrm{E}-\mathrm{BP}$ is inactive in translation initiation. Both currently recognized complexes of mTOR (mTORC1, loosely associated with growth and mTORC2, loosely associated with cell survival and apoptosis resistance) can phosphorylate 4E-BP. ${ }^{100}$ Unphosphorylated 4E-BP has non-covalent affinity to and prevents transcription initiation activity of eIF4E. When phosphorylated, 4E-BP1 loses that affinity and separates from eIF4E, thereby allowing eIF4E to function in cap-dependent mRNA translation. ${ }^{97,99-101}$

MAP kinase interacting kinases (hereafter referred to as $\mathrm{MNK}$ ) can also phosphorylate 4E-BP, releasing it from eIF-4E. ${ }^{99,102-105}$ A wide variety of internal and extracellular events converge on $\mathrm{mTOR}$ and/or MNK to enhance or inhibit their activity. Development of resistance to mTOR inhibitors such as everolimus is often caused by eIF4E amplification or MNK upregulation. ${ }^{97,105}$

eIF4E overexpression has been identified in $30 \%$ of human cancers generally, ${ }^{97,106-110}$ including in invasive breast cancer where the degree of eIF4E, both gene and protein overexpression, has been positively correlated with occurrence, recurrence, and metastasis. ${ }^{11-118}$ eIF4E protein expression was associated with shorter survival, higher tumor mitotic index, and higher-grade breast cancer. ${ }^{115}$ Increased phosphorylated 4E-BP confers a worse prognosis and faster disease progression in breast, ovary, and prostate cancers. ${ }^{103}$

A crucially important oddity of eIF4E in breast cancer is the homogenous spatial uniformity of phosphorylated eIF4E protein overexpression in breast cancer tissues, both metastatic and primary. ${ }^{116}$ This is particularly notable given the spatial heterogeneity of ER, PR, HER2, mTOR, and other commonly overexpressed markers in breast cancer.

In addition, in 200 patients with Stage 4 breast cancer, immunohistochemistry analysis revealed that greater increase in eIF4E phosphorylation in response to chemotherapy with doxorubicin, cyclophosphamide, or FU was correlated with shorter median overall survival, ${ }^{114} 4.7$ years in patients with a two- to fourfold increase in eIF4E phosphorylation versus 3.1 years in patients with a 9-11-fold increase. A second study a few years later found similar results. ${ }^{118}$ Among patients undergoing primary debulking for a node-positive breast cancer when nodes were positive, after 4-year followup, systemic recurrence occurred in $22 \%$ of women with low eIF4E protein expression, $27 \%$ of the intermediate group, and in $49 \%$ expressing large amounts of eIF4E. ${ }^{119}$ Even more serious was the presence of multiple distant metastases in $60 \%$ of women whose primary expressed large amounts of eIF4E but in $15 \%$ of women whose primary expressed low amounts of eIF4E, again after 4-year follow-up. ${ }^{119}$

In an unusually exciting and instructive study, Li et al ${ }^{120}$ studied breast cancer biopsy tissue by immunohistochemistry both before and after chemotherapy. After cytotoxic chemotherapy with doxorubicin, or cyclophosphamide or 5-FU, the expression of phosphorylated eIF4E increased in the posttreatment biopsy material, as given in the "Chemotherapy triggers EMT" section, and chemotherapy-activated Wnt/beta-catenin, as given in the "Rifabutin: $847 \mathrm{Da}, 2$-day half-life" section, signaling in a phosphorylated eIF4E-dependent manner. ${ }^{120}$

Although the significance of eIF4E phosphorylation or its range of functions is not fully understood, some aspects are predominantly the empirical data in the abovementioned paragraph. Regulation of eIF4E function is partly achieved through this phosphorylation process. Untreated GBMs show an excess of phosphorylated (unbound) 4E-BP. ${ }^{98,102}$ Inhibition of 4E-BP phosphorylation with consequent retention of its association with 4E-BP leads to inhibition of protein synthesis, inhibition of glioma cell proliferation in vitro, and tumor growth in vivo, in an orthotopic GBM mouse model..$^{98,102}$ We know ribavirin gets good brain tissue levels based on the psychiatric morbidities associated with its use in treating hepatitis $\mathrm{C}$. Volpin et $\mathrm{al}^{121}$ suggested using ribavirin to treat GBM based on these considerations. 
That metformin inhibits 4E-BP1 phosphorylation via mTOR inhibition ${ }^{122}$ makes metformin a good coordinated partner drug to ribavirin. That ribavirin also inhibits MNK and since MNK phosphorylation of eIF4E is an alternate eIF4E activation pathway particularly used during the development of resistance to the mTOR inhibitor everolimus, ${ }^{98,99,102,123,124}$ ribavirin might be combined with everolimus or metformin to advantage. This would be a good example of the phenomenon mentioned in the "Introduction" section that when one growth pathway is pharmacologically blocked other parallel growth-driving pathways can become active, taking the place of blocked paths. mTOR phosphorylates 4E-BP1, or if mTOR is inhibited then MNK can take over, phosphorylating 4E-BP1. This would also explain why and how mTOR inhibitors have not been successful in treating some tumors such as GBM even though they express an overabundance of mTOR. MNK simply takes over when mTOR is blocked.

TGF-beta promotion of EMT that occurs largely through phosphorylation of eIF4E by MNK (with multiple intermediates between the two $)^{103}$ makes pirfenidone a good partner drug for both metformin and ribavirin.

In addition, experimental MNK inhibitors decrease eIF4E phosphorylation levels in breast cancers, ${ }^{120}$ and GBM, ${ }^{98}$ where MNK inhibition enhanced temozolomide cytotoxicity. In parallel fashion, in 103 cases of astrocytomas, high expression of phosphorylated eIF4E was significantly correlated with shorter overall survival rates. ${ }^{107}$

All treated breast cancers were found to overexpress phosphorylated (activated) eIF4E, ${ }^{116,120}$ a remarkable and unique finding in any cancer. Decreased eIF4E phosphorylation in breast cancer also resulted in increased E-cadherin and betacatenin protein levels ${ }^{125}$ reflecting a shift from mesenchymal toward epithelial attributes. The abovementioned combined data suggest that ribavirin could be of potential benefit by inhibiting eIF4E in breast cancer. Kentsis et al ${ }^{126,127}$ have demonstrated that ribavirin inhibits $\mathrm{m}^{7} \mathrm{G}$ mRNA cap binding to eIF4E. Ribavirin directly bound to eIF4E with a micromolar affinity at the functional site used by $\mathrm{m}^{7} \mathrm{G}$ mRNA cap, reducing eIF4E/mRNA binding and disrupting the translation process. Of note, not all mRNA translation is eIF4E dependent, but important mRNAs in breast cancer are, for instance, the one coding cyclin D1/3, c-Myc, VEGF, FGF2/4, and MCL-1. Some preclinical studies in several murine models of breast cancer revealed that ribavirin inhibits breast cancer cell proliferation through eIF4E blockage. ${ }^{128,129}$ Moreover, in these studies, multiple-aspect characteristics of EMT were reversed or diminished by ribavirin. ${ }^{128,129}$

More recently, two studies demonstrated significant glioma cell killing by ribavirin, ${ }^{121,130}$ confirming a 2014 study showing that ribavirin induced $\mathrm{G} 0 / \mathrm{G} 1$ arrest in seven glioma cell lines at a median $55 \mu \mathrm{M} \mathrm{IC}_{50}$ (range 28-664). ${ }^{131}$ This latter study positively correlated mRNA expression of PDGF receptor-alpha, a major driver of GBM growth, with better glioma cell sensitivity (lower $\mathrm{IC}_{50}$ ) to ribavirin. That PDGF receptor is also a major driver of breast cancer ${ }^{132,133}$ and can cross cover for the $\mathrm{ER}^{134,135}$ forming one of the many escape paths from aromatase inhibitor suppression of breast cancer growth. This fact favors the possibility of this path contributing to ribavirin's inhibitory effect in breast cancer as well.

Similar to the abovementioned data on breast cancer, targeting eIF4E using ribavirin to block migration and EMT in NSCLC has been highlighted. ${ }^{136}$ In this study, inhibition of eIF4E after ribavirin treatment led to decreased migration, differentiation, and expression of several EMT-related genes such as ERa, SMAD5, NF- $K B$, cyclin D1, $c-M Y C$, or $H I F-1 a .{ }^{136}$ As we expect to do but using ribavirin, an engineered short hairpin RNA interfering with eIF4E transcription inhibited breast cancer cell migration, primary tumor growth, and metastasis establishment. ${ }^{137}$

TGF-beta-induced eIF4E phosphorylation enhanced metastases, invasion, and EMT in a mouse breast cancer model, all of which were inhibited when an un-phosphorylatable eIF4E was present. ${ }^{138}$

IMPDH is a pivotal enzyme for biosynthesis of GTP and is frequently increased in tumor cells. ${ }^{139}$ It has been shown that ribavirin via IMPDH inhibition was effective against chronic lymphocytic leukemia cells. ${ }^{140}$ Recently, Isakovic et $\mathrm{l}^{130}$ demonstrated in glioma cells that ribavirin inhibits IMPDH activity and induces autophagy inhibiting the activity of mTORC1 and the SRC/AKT pathway.

Of deep significance for understanding breast cancer growth and the ABC7 regimen to inhibit it, is the study by Decarlo et al, ${ }^{141}$ where they demonstrated a feed-forward amplification loop between TGF-beta and eIF4E (that we intend to block with pirfenidone and ribavirin, respectively). In addition, TGF-beta agonism drives eIF4E activation ${ }^{138}$ confirming pirfenidone as a good partner drug for ribavirin.

Ribavirin has also been shown to inhibit mTOR/eIF4E signaling increasing paclitaxel and imatinib activity in squamous cell carcinoma ${ }^{142}$ and leukemic cells, ${ }^{124}$ respectively.

Discussion here of ribavirin strikes at the heart of why pharmaceutical mTOR inhibitors such as everolimus have not been as clinically useful as the biochemistry of cancer indicates it should be. The data in this section paint a consistent picture of eIF4E as a central element in breast cancer malignancy degree and as such a worthwhile target to inhibit. Ribavirin can be expected to do this effectively but it will be the most difficult of the $\mathrm{ABC} 7$ drugs to tolerate. Ribavirin is 
the problematic drug of $\mathrm{ABC} 7$. When used over months to treat hepatitis $\mathrm{C}, 1000 \mathrm{mg} /$ day would have been a common dose. Depressed mood, anemia, weight loss, and a severe but ill-defined malaise were common side effects and not rarely required dose reduction or even stopping ribavirin entirely. ${ }^{143}$ Given ribavirin's propensity to give unpleasant side effects, it should be increased with caution from starting dose of $100 \mathrm{mg}$ once daily with frequent mood and CBC evaluations.

\section{Rifabutin: 847 Da, 2-day half-life}

Rifabutin is an old antibiotic closely related to the even older drug rifampin (same as rifampicin). Rifabutin is active against Mycobacterium tuberculosis, atypical mycobacteria, staphylococci, group A streptococci, Neisseria gonorrhoeae, Neisseria meningitidis, Haemophilus influenzae, Haemophilus ducreyi, Campylobacter spp., Helicobacter pylori, chlamydia, and Toxoplama gondii. ${ }^{144,145}$

In 2016, rifabutin was reported to have blunted the growth of a patient's NSCLC, subsequently studied in vitro and found to be active in inhibiting lung cancer cell growth and suppressing Ki67 staining. ${ }^{146}$ Rifabutin suppressed eIF4E phosphorylation with consequent decreased beta-catenin phosphorylation and increased beta-catenin destruction consequent to that. ${ }^{146}$ Thus, rifabutin could coordinate to advantage with ribavirin to thoroughly block eIF4E.

Erlotinib inhibits epidermal growth factor receptors (HER1, EGFR) and is effective initially in stopping some lung cancers' growth. As resistance to erlotinib develops, EGFR mutations resulting in EGFR affinity to beta-catenin, thereby shifting growth drive to beta-catenin system. ${ }^{147,148}$ eIF4E-beta-catenin axis is inhibited by several of the ABC7 drugs.

BCL6 is a $95 \mathrm{kDa}$ protein transcription factor of selected genes, inhibiting expression of some and triggering transcription of others' in cancers generally ${ }^{149}$ and in breast cancer specifically. ${ }^{150-152}$ The result is a BCL-6-mediated antiapoptosis effect. Breast cancer cells' survival is enhanced by BCL6. ${ }^{151}$ Rifabutin binds to BCL6, preventing its function in translation inhibition. ${ }^{153}$ This would be expected to be of benefit on multiple accounts during breast cancer treatment. Interestingly, miR-544 inhibition of BCL6 in TNBC cells inhibited proliferation, migration, and invasion in vitro. ${ }^{154}$ BCL6 promoted invasion, migration, and EMT marker expression in breast cancer with indication that greater expression of BCL-6 correlates with shorter overall survival in breast cancer. ${ }^{150}$

Not all malignant cells within a strongly ER+ breast cancer will express ERs. The minority population not expressing
ERs is relatively chemotherapy resistant with some of that extra chemotherapy resistance mediated by upregulated BCL-6 specifically in that subpopulation. ${ }^{155}$

\section{Metformin: I29 Da, not metabolized, 6-hour half-life}

Metformin is the most prescribed initial drug treatment for type 2 diabetes worldwide. Despite 60 years of use, the mechanism of action in lowering average glucose is not entirely clear. ${ }^{156}$ Hepatic gluconeogenesis is decreased by metformin and insulin sensitivity is increased but how that occurs is uncertain. Metformin in vivo and in vitro increases AMPK, a major regulator of energy homeostasis, metabolism, and protein synthesis. ${ }^{156}$ Thus, activated AMPK results in inhibition of mTOR. Breast cancer cell expression of beta-catenin was decreased by metformin concomitantly and proportionately to AMPK phosphorylation. ${ }^{157}$

Decreased insulin/insulin-like growth factor-I signaling and inhibition of mitochondrial electron transport chain complex are other documented actions of metformin. Across many cancers, a large chart review has shown decreased mortality in patients treated with metformin. ${ }^{158}$ Experimental data support the notions that increased lactate secretion, reduced oxygen consumption, and activated AMPK signaling are plausible mechanisms for metformin's anticancer effects. ${ }^{159}$ Metformin also decreased breast cancer cells' intracellular adenosine triphosphate, viability, and anti-apoptotic protein BCL6 concomitant with increased intracellular ROS, ${ }^{160}$ the conclusion being that metformin acts primarily on mitochondria, other effects being secondary to that. That work confirmed a related earlier breast cancer study where the mode of viability loss mediated by metformin was found to be by oxidative stress increase and BCL-2 decrease. ${ }^{161}$

Silvestri et al ${ }^{162}$ showed that metformin was indeed cytotoxic to breast cancer cells but 1) only in low glucose conditions - high glucose in vitro could subvert metformin's growth inhibition and 2) although AMPK activation was a requirement for cytotoxicity, mTOR was not. However, $\mathrm{Wu}$ et $\mathrm{al}^{163}$ showed that metformin both increased lifespan of the nematode Caenorhabditis elegans and showed growth inhibition of pancreatic cancer and melanoma cells by an AMPK-independent interference with mitochondrial respiration mechanism. Likewise, Ben Sahra et al ${ }^{164}$ demonstrated that metformin cytotoxicity to androgen-sensitive human prostate adenocarcinoma cells was AMPK independent but mTOR inactivation dependent. Furthering complicating delineation of metformin's mechanism of action in treating cancer, Gui et al ${ }^{165}$ showed that metformin's anticancer effect 
was by inhibiting mitochondrial regeneration of oxidized NAD+ regeneration and lowering aspartate levels.

Just in 2016, five extensive reviews appeared recounting evidence favoring the use of metformin as treatment adjunct in cancer generally. ${ }^{16-170}$

In a study particularly relevant to $\mathrm{ABC} 7$ regimen considering that capecitabine metabolizes into 5-FU within cancer cells, Qu et a ${ }^{171}$ showed that breast cancer cells that had become resistant to 5-FU regained cytotoxic sensitivity to 5 -FU by simultaneous exposure with metformin. Metformin synergy with 5-FU could also be demonstrated to breast cancer cells in both the stem and non-stem subpopulations. ${ }^{172}$ Of central importance to the $\mathrm{ABC} 7$ regimen, $\mathrm{IC}_{50}$ of $5-\mathrm{FU}$ to esophageal cancer cells was lowered by metformin ${ }^{173}$ and correlated with increased AMPK activation and decreased mTOR function and lactate production. Metformin plus 5-FU combination was also active in slowing esophageal cancer growth in a xenotransplant model more than either agent alone. ${ }^{174}$

YAP is a small protein transcription factor promoting the growth of many cancers. When phosphorylated, it is retained in cytoplasm and therefore nonfunctional in promoting growth or inhibiting apoptosis. Metformin treatment of hepatocellular carcinoma patients increased YAP phosphorylation via AMPK phosphorylation and prolonged survival, half deceased at $\sim 31$ months without compared to $\sim 44$ months with metformin. ${ }^{175}$ Adding metformin to exemestane also increased survival in ER+ breast cancers that overexpressed IGF1R. ${ }^{176}$

An ongoing trial (ClinicalTrials.gov Identifier NCT01589367) is studying potential survival benefits of adding metformin $2000 \mathrm{mg}$ /day to standard antiestrogen aromatase inhibitor, letrozole $2.5 \mathrm{mg} /$ day, in nondiabetic postmenopausal women with ER+ breast cancer.

Preoperative treatment of breast cancer patients with metformin has given mixed results. Some studies showed reduced mitotic rate after metformin $2000 \mathrm{mg} / \mathrm{day}^{177}$ and $1500 \mathrm{mg} /$ day, ${ }^{178}$ while others showed no reduction using $1500 \mathrm{mg} /$ day. ${ }^{179}$ A similarly designed study using $1700 \mathrm{mg} /$ day found marginally lower Ki67 only in women with increased insulin resistance. ${ }^{180}$

A pivotal study supporting metformin use during the treatment of breast cancer was reported back in 2011. In women undergoing primary resection for breast cancer, $1 \mathrm{~g}$ twice daily metformin was given 14 days prior to surgery. ${ }^{177}$ By immunohistochemistry, the diagnostic biopsy was compared to resected tissue for p-AMPK, p-AKT, insulin receptor, cleaved caspase-3, and Ki67. In metformin pretreated, increased p-AMPK and decreased p-AKT were seen compared to those not treated with metformin in the interval between biopsy and surgery. Ki67 and cleaved caspase-3 were diminished in metformin-treated women compared to those not so treated. These changes were not large but were statistically significant and large enough to expect some clinical benefit. ${ }^{177}$

Although metformin decreases breast cancer cell survival in vitro, ${ }^{160-162,181}$ the clinical benefit would seem small given the equivocal human trials and evidence that the small benefit seen tended to be restricted to diabetic/prediabetic people. However, small benefit is not no benefit.

Metformin despite being hydrophilic achieves approximately equal plasma and brain tissue levels. In rats, after single-dose oral metformin administration, $28 \mu \mathrm{mol} / \mathrm{L}$ plasma and $14 \mathrm{nmol} / \mathrm{g}$ brain tissue $(14 \mu \mathrm{M})$ were seen. ${ }^{182}$ Average metformin plasma levels typically seen in asymptomatic diabetes patients were $2.7 \pm 7.3 \mathrm{mg} / \mathrm{L}, \sim 3 \mu \mathrm{M}$. The unusually wide drug range seen, $\pm 7.3 \mathrm{mg} / \mathrm{L}( \pm 57 \mu \mathrm{M})$, reflects metformin's safety. ${ }^{183}$ Metformin's side effects are limited to diarrhea, nausea, and vomiting. Some cases of lactic acidosis could occur but at a low frequency and when metformin is implicated as the cause of lactic acidosis, metformin plasma levels greater than $5 \mu \mathrm{g} / \mathrm{mL}$ are generally found. Target dose of metformin is the standard dose used in past breast cancer studies of metformin - 1700-2000 mg/day.

\section{Propranolol: 259 Da, cyp IA2, 2D6, 9-hour half-life}

Propranolol was the first beta-blocker introduced to clinical practice. Introduced in the $1960 \mathrm{~s}$, it is still in wide use to treat hypertension, migraine, angina, selected arrhythmias, essential tremor, resolution of infantile hematomas, and in reducing the cardiac effects (tachycardia) due to acute anxiety. Propranolol's general cancer process inhibiting attributes were recently reviewed. ${ }^{184}$ Below are selected data supporting propranolol's use specifically as adjunct in breast cancer treatment.

A study of 404 breast cancer patients to compare the proliferation rates of breast cancers in women who had taken beta-blockers compared to those who had not found a clear reduction in Ki67 only in those with Stage 1 disease. ${ }^{185}$ A single ER+, HER2- patient was treated with 25 days of propranolol $1.5 \mathrm{mg} / \mathrm{kg}$ per day after diagnostic biopsy but before resection. Resection of tumor tissue showed a $23 \%$ reduction in Ki67 staining compared to biopsy tissue 25 days earlier, before any propranolol. ${ }^{185}$ Of important note, beta1-selective beta-blockers did not work to reduce Ki67, only 
nonselective beta-blockers did. However, a large European epidemiological study found no survival benefit from propranolol use after a breast cancer diagnosis. ${ }^{186}$

Of particular interest to $\mathrm{ABC} 7$ regimen, Rico et $\mathrm{al}^{187}$ examined the effects of metformin and propranolol singly and combined in several preclinical TNBC models, finding additive to synergistic growth-inhibiting effects.

In a cohort of 800 women with early TNBC, 9\% used beta-blockers. The beta-blocker use and nonuse groups were well matched. At 5 years, $19 \%$ of the nonusers had died of breast cancer while $8 \%$ of beta-blocker users had died of breast cancer. ${ }^{188}$

In examining a cohort of 1971 multiple myeloma patients, those who took any beta-blocker, had a $24 \%$ disease-specific mortality at 5 years. Those who took a beta-blocker plus other cardiac drugs had $32 \%$ while those on no cardiac or blood pressure medicines had $41 \%$ myeloma-specific mortality at 5 years. ${ }^{189}$

An interesting study from Choy et $\mathrm{al}^{190}$ showed that among 1000 breast cancer patients those on a beta-blocker had a lower recurrence rate, and specifically TNBC expressed particularly high levels of beta-adrenergic receptors. Their brain metastases expressed more beta-adrenergic receptors per cell than did the primary tumors. ${ }^{190}$ This study also gave evidence of propranolol's inhibition of proliferation and migration in breast cancer cells expressing the beta-adrenergic receptor.

In reviewing seven epidemiological studies prior to 2015 on beta-blocker use in breast cancer, Childers et al ${ }^{191}$ concluded that, although results were mixed between these studies, slightly lower risk of death was associated with betablocker use. Beta-blocker use is associated with improved relapse-free survival (but not in overall survival) also in patients with TNBC. ${ }^{192}$

Bone is richly supplied with sympathetic nerve endings. When specifically osteoblasts' beta-adrenergic receptor is stimulated by norepinephrine from these nerve endings, the osteoblasts secrete RANKL. ${ }^{193}$ Thus, propranolol should harmonize with quetiapine (vide supra) in treating and preventing bone metastases in breast cancer. CA125 is a high molecular weight mucin commonly elevated in ovarian cancer. Patients given perioperative propranolol showed an $83 \%$ CA125 decrease on postoperative day 7 when those given placebo had a $72 \%$ decrease. ${ }^{194}$

Although the data were mixed, a review of 10 studies completed by 2015 of beta-blocker use in breast cancer concluded that specifically propranolol use was indeed associated with slightly reduced breast cancer-specific mortality. ${ }^{195}$
Propranolol-blocked beta-adrenergic agonist induced increased migration and decreased breast cancer cell-to-cell adhesion. ${ }^{196}$ Propranolol inhibited breast cancer cell migration in vitro. ${ }^{197}$ Breast cancer cells express beta-adrenergic receptors. Blocking these with propranolol lowers their glucose uptake. ${ }^{198}$

Campbell et al ${ }^{199}$ demonstrated that beta-adrenergic stimulation of bone increased osteoblasts' RANKL expression. That induced RANKL increased breast cancer establishment of metastases in bone. ${ }^{199}$ Thus, the combination with quetiapine might be particularly beneficial.

Beta-adrenergic stimulation did not change the growth of an orthotopic murine breast cancer but did induce a remarkable 30-fold increase in metastases, an effect partially blocked by propranolol. ${ }^{200}$ Of clinical importance to ABC7, Shaashua et $\mathrm{a}^{201}$ showed that combining propranolol with a COX-2 inhibitor in perioperative breast cancer decreased EMT, serum IL-6, and C-reactive protein levels.

There is risk of symptomatic iatrogenic hypotension with propranolol. The propranolol dose must therefore be slowly uptitrated as tolerated, monitoring blood pressure.

\section{Capecitabine: $359 \mathrm{Da}$, half-life $<$ I hour}

Capecitabine is a 359 Da pro-drug giving rise to intracellular release of $130 \mathrm{Da} 5$-FU. ${ }^{202,203} 5$-FU inhibits thymidylate synthase, which mediates the synthesis of thymidine monophosphate, the active form of thymidine required DNA synthesis.

Despite $\sim 20$ years of clinical use in treating breast cancer, there remains some unclarity on the ideal dosing schedule for capecitabine. ${ }^{204-206}$ A comparison of cycles of $1000 \mathrm{mg} / \mathrm{m}^{2}$ twice daily for 14 days, 7 days off with $1250 \mathrm{mg} / \mathrm{m}^{2}$ twice daily for 14 days, and 7 days off indicated lower side effect burden with $1000 \mathrm{mg} / \mathrm{m}^{2}$ twice daily. ${ }^{207,208}$

Several reports indicate that dosing capecitabine at just high enough level to generate palmar-plantar erythrodysesthesia might be most effective dosing regimen. ${ }^{206,209}$ This would be analogous to erlotinib dosing where titrating to rash might be most effective. ${ }^{210}$

Capecitabine is best given with Coke ${ }^{\mathrm{TM}}$ or fresh squeezed lemon juice to assure low enough gastric $\mathrm{pH}$ for adequate and uniform absorption. This would be particularly important for those on proton pump inhibitors.

Principle toxicity is palmar-plantar erythrodysesthesia (synonyms hand-foot syndrome or chemotherapy induced acral erythema), diarrhea, and nausea, although cytopenias, fatigue, dyspnea, or cardiac abnormalities can be seen. ${ }^{211}$ The common dose for capecitabine in breast cancer is $1250 \mathrm{mg} / \mathrm{m}^{2}$ orally twice daily for 14 days, none for 7 days, every 21 days. 


\section{Agomelatine: $243 \mathrm{Da}$, 2-hour half-life}

Agomelatine is a 243 Da pharmaceutical melatonergic agonist at both melatonin's receptors, M1 and M2. ${ }^{212}$ It has many advantages over the use of melatonin itself $\mathrm{f}^{213,214}$ In short, these advantages are: 1) agomelatine is Health Canada and EMA approved and marketed as an antidepressant. As such, it is a well-standardized product, as opposed to over-thecounter melatonin preparations which are exempt from the strict standards of approved medicines; 2) agomelatine has considerably tighter affinity to both M1 and M2 receptors than does the natural ligand (melatonin); 3) agomelatine has a much longer dwell time in the body than does melatonin, and; 4) absorption is more uniform and reliable than is absorption of melatonin.

Although agomelatine is available for import into the USA, it is not FDA approved. Ramelteon is an equally potent melatonergic agonist at M1 and M2 as is agomelatine. Ramelteon is FDA approved and marketed in the USA. It has similar actions and advantages over melatonin as does agomelatine ${ }^{213,215}$ and can be substituted for agomelatine in the $\mathrm{ABC} 7$ regimen.

Elevation of hepatic transaminases is of potential concern when using agomelatine. This requires regular monitoring. Elevation is dose dependent, occurring in $\sim 3 \%$ of those receiving $50 \mathrm{mg}$ once at bedtime. ${ }^{216}$ It is usually reversible.

Work pointing to diminished breast cancer cell malignant behavior during exposure to melatonin dates back at least 3 decades. ${ }^{217}$ There are numerous studies about oncostatic effects of melatonin on several tumors as well as recent reviews summarizing the different mechanisms of cancer inhibition by melatonin. ${ }^{84,218-221}$ These include regulation of estrogen pathway, melatonin as SERM and SEEM, modulation of the cell cycle, differentiation and the induction of apoptosis, inhibition of telomerase activity, inhibition of oxidative stress, inhibition of angiogenesis, regulation of circadian rhythms, avoidance of circadian disruption, inhibition of tumor metastasis, invasiveness and motility decline, and enhancement of immune system and epigenetic regulation. ${ }^{218,221}$

Briefly and empirically, melatonin has readily demonstrable growth-inhibiting effects in both in vivo animal models, with chemically induced mammary tumors in rodents, and in vitro assays in estrogen-positive human breast cancer cells. ${ }^{221-224}$ Melatonin inhibits invasive and metastatic properties of human breast cancer cells in different xenograft models. ${ }^{225-228}$ Due to the broad spectrum of melatonin's actions, the mechanisms through which it interferes with metastases are varied. These include modulation of cell-cell and cell-matrix interaction, extracellular matrix remodeling by matrix metalloproteinases, cytoskeleton reorganization, EMT, and angiogenesis. ${ }^{229}$

Melatonin shifts human breast cancer cells to a lower invasive status by upregulating E-cadherin and $\beta 1$-integrin expression and decreasing OCT4, N-cadherin, and vimentin. ${ }^{219,227,228,230}$ These findings suggest that melatonin modulates both cell-cell and cell-matrix interactions in breast cancer and reduces the metastatic potential of the tumor. Melatonin also has regulatory actions on matrix metalloproteinases in breast cancer. It has been described that melatonin inhibits the induction, catalytic activity, and expression of MMP-9 and MMP-2.229,231 In addition to modulating the metalloproteinase activity, melatonin reduces cancer cell migration through the downregulation of ROCK-1 and MCLCK, two kinases that control the cytoskeletal rearrangement associated with cell-cell and cell-matrix adhesion. ${ }^{229,232}$ The attenuation of HER2-Rsk2 signaling by melatonin plays a main role in the melatonin-mediated suppression of EMT and late-staged metastasis in breast cancer cells. ${ }^{226,229}$

In tumor angiogenesis, there is a crosstalk between cancer cells and surrounding endothelial cells. Melatonin interferes in the paracrine interactions between malignant epithelial cells and proximal endothelial cells through a downregulatory action on VEGF expression in human breast cancer cells, which decrease the levels of VEGF around endothelial cells. ${ }^{230,231}$ In addition, melatonin directly exerts antiangiogenic actions by reducing endothelial cell proliferation, invasion, migration, and tube formation, through a downregulation of VEGF expression. ${ }^{219,233-235}$ Melatonin also impedes the EMT process and cancer cell dissemination through downregulatory actions of the p38 pathway ${ }^{227}$ and interferences with NF- $\kappa B$ signaling in tumor cells. ${ }^{217,229,236}$

Recently, a review of the effects of melatonin and chemotherapeutic agents in combination in cancer treatments has been published. ${ }^{237}$ Although the information available is limited, the results obtained suggest that melatonin sensitizes tumor cells to the cytotoxic effects of chemotherapeutic agents.

In addition, in a rat ER+ breast cancer model, melatonin reduced tumor weight, prolonged survival, and increased E-cadherin without giving apparent side effects. ${ }^{238}$ In this model, doxorubicin cytotoxicity to the breast cancers was augmented by giving simultaneous melatonin. ${ }^{238}$ Melatonin reduced in vitro migration and in vivo growth, proliferation index, and metastases in a murine xenograft model. ${ }^{232}$

Of particular relevance to $\mathrm{ABC} 7$, earlier in year 2017, melatonin was shown to increase 5-FU inhibition of colon cancer cell proliferation, in vitro colony formation, migration, 
and invasion, showing a corresponding in vivo synergy with 5 -FU in colon cancer tumor growth inhibition in a xenograft model. ${ }^{239}$

Similarly, melatonin moderately enhanced cytotoxicity to cisplatin and doxorubicin, while slightly but significantly enhancing 5-FU cytotoxicity to HeLa cells. ${ }^{240}$ In an in vitro study, in rat pancreatic adenocarcinoma, melatonin augmented cytotoxicity of 5-FU, cisplatin, and doxorubicin. ${ }^{241}$ Melatonin decreased pancreas cancers in hamsters given a carcinogen ( $\mathrm{N}$-nitrosobis (2-oxopropyl) amine), as did capecitabine. Giving both melatonin and capecitabine decreased this incidence further. ${ }^{242}$ Melatonin augmented doxorubicin cytotoxicity to lymphocytic leukemia cells without having cytotoxicity to normal lymphocytes. ${ }^{243}$

Melatonin sensitized human breast cancer cells to radiation via 1) reduction in estrogen-synthesizing proteins, and 2) induction of a twofold change in p53 expression, and 3) downregulation of proteins involved in double-strand DNA break repair, such as RAD51 and DNA-PKcs. ${ }^{244}$ Melatonin enhanced cytotoxicity of 5-FU to esophageal squamous carcinoma cells both in vitro and in a xenograft model. ${ }^{245}$ These authors used $20 \mathrm{mg}$ / $\mathrm{kg}$ per day melatonin in the xenograft model, corresponding to a nominal $1400 \mathrm{mg} /$ day for a $70 \mathrm{~kg}$ adult human. The common over-the-counter melatonin used is $3-20 \mathrm{mg}$ once at bedtime. The tighter affinity to melatonin receptors and much longer half-life of agomelatine compared to melatonin would go some of the way toward generating a stronger agonist signal to M1 and M2 than today's commonly used melatonin doses. Another felicitous aspect of melatonergic agonism is a potential increase in NK cell numbers and function. ${ }^{246}$

A remarkable epidemiological study of cancer-free postmenopausal women showed that higher urinary melatonin levels were associated with a slightly reduced risk of later developing breast cancer, ${ }^{247}$ although these data are not uncontested. A review of all studies on urinary melatonin would indicate that this matter remains unsettled. ${ }^{248}$

The suggested dose of agomelatine is $50 \mathrm{mg}$ once at bedtime, twice the EMA and Health Canada recommended dose for treating depression. If ramelteon is used instead $16 \mathrm{mg}$ at bedtime, twice the FDA-approved dose is recommended.

\section{Conclusion}

Once breast cancer has metastasized to bone, liver, or lungs, the prognosis becomes poor. No current treatment has a reliable and robust disease control rate at that point.

Animal study of the complete $\mathrm{ABC} 7$ regimen would be advisable. Based on clinical experience with these drugs individually and in pairs in general medical practice, the predicted safety and tolerability of the $\mathrm{ABC} 7$ regimen should be safe. As a further safety measure, the ABC7 drugs should be added one at a time at weekly intervals, thereby catching any unwanted interactions early and the offending drug more easily identified.

In this article, we propose that seven common and already FDA-approved drugs, such as agomelatine (or ramelteon), metformin, pirfenidone, propranolol, quetiapine, ribavirin, and rifabutin, can have the ability to reduce EMT and breast cancer cell tumorigenesis. These ancillary drugs have demonstrated that attributes that we have reason to believe will inhibit EMT and enhance capecitabine's efficacy. The predicted safety and tolerability of the $\mathrm{ABC} 7$ regimen is good. A clinical trial is warranted given the fatal outcome of metastatic breast cancer as things now stand.

\section{Abbreviations}

ABC7, Adjuvant for Breast Cancer treatment using seven repurposed drugs; $\mathrm{AMPK}, \mathrm{AMP}$-activated protein kinase; BCL-6, B-cell lymphoma-6; CBC, complete blood count; COMBAT regimen, combined oral metronomic biodifferentiating antiangiogenic treatment regimen; CSCs, cancer stem cells; CTCs, circulating tumor cells; CUSP9 regimen, coordinated undermining of survival paths with nine regimens; EGFR, epidermal growth factor receptor; EMA, European Medicines Agency; EMT, epithelial-to-mesenchymal transition; ER, estrogen receptor; ER+, ER positive; 4E-BP, eIF4Ebinding protein; 4E-BP1, eIF4E-binding protein-1; FDA, Food and Drug Administration; 5-FU, 5-fluorouracil; GBM, glioblastoma; GM-CSF, granulocyte-monocyte colonystimulating factor; GTP, guanosine-5' -triphosphate; HER2, human epidermal growth factor receptor 2; Hh, hedgehog; $\mathrm{HR}$, hormone receptor; $\mathrm{HR}+$, hormone receptor positive; $\mathrm{HR}-$, hormone receptor negative; IGF1R, insulin-like growth factor type 1 receptor; IL-6, interleukin-6; IMPDH, inosine monophosphate dehydrogenase; MCLCK, myosin lightchain kinase; MEMMAT regimen, metronomic and targeted anti-angiogenesis therapy regimen; MET, mesenchymal-toepithelial transition; MNK, MAP kinase-interacting kinase; mTOR, mammalian target of rapamycin; MTZ regimen, minocycline telmisartan and zoledronic acid regimen; $\mathrm{m}^{7} \mathrm{G}$, 7-methylguanosine; NAD+, nicotinamide adenine dinucleotide; NCATS, National Center for Advancing Translational Sciences; NK, natural killer; NSCLC, non-small cell lung cancer; OPG, osteoprotegerin; PDGF, platelet-derived growth factor; PR, progesterone receptor; RANK, receptor activator of nuclear factor- $\kappa B$; RANKL, RANK ligand; ROCK-1, rho-associated protein kinase; ROS, reactive oxygen species; 
SEEM, selective estrogen enzyme modulator; SERM, selective estrogen receptor modulator; TGF-beta, transforming growth factor-beta; Th, T helper; TNBC, triple-negative breast cancer; ZO-1, zonula occludens-1.

\section{Acknowledgments}

SC was supported by grants from the Spanish Economy and Competitiveness Ministry (SAF2016-77103-P) and from Instituto de Investigación Sanitaria Valdecilla (IDIVAL) (APG/12). YS was supported by the Department of Defense (W81XWH-14-1-0403), the Wake Forest School of Medicine Internal Pilot Funding, and the Translational Research Academy which is supported by the NCATS, National Institutes of Health, through Grant Award Number UL1TR001420.

\section{Disclosure}

The authors report no conflicts of interest in this work.

\section{References}

1. Jerusalem G, Bachelot T, Barrios C, et al. A new era of improving progression-free survival with dual blockade in postmenopausal HR(+), HER2(-) advanced breast cancer. Cancer Treat Rev. 2015;41(2):94-104.

2. Schulz M, Iwersen-Bergmann S, Andresen H, Schmoldt A. Therapeutic and toxic blood concentrations of nearly 1,000 drugs and other xenobiotics. Crit Care. 2012;16(4):R136.

3. Salacz ME, Kast RE, Saki N, Brüning A, Karpel-Massler G, Halatsch ME. Toward a noncytotoxic glioblastoma therapy: blocking MCP-1 with the MTZ regimen. Onco Targets Ther. 2016;9:2535-2545.

4. Zapletalova D, Andre N, Deak L, et al. Metronomic chemotherapy with the COMBAT regimen in advanced pediatric malignancies: a multicenter experience. Oncology. 2012;82(5):249-260.

5. Kast RE, Boockvar JA, Brüning A, et al. A conceptually new treatment approach for relapsed glioblastoma: coordinated undermining of survival paths with nine repurposed drugs (CUSP9) by the International Initiative for Accelerated Improvement of Glioblastoma Care. Oncotarget. 2013;4(4):502-530.

6. Kast RE, Karpel-Massler G, Halatsch ME. CUSP9* treatment protocol for recurrent glioblastoma: aprepitant, artesunate, auranofin, captopril, celecoxib, disulfiram, itraconazole, ritonavir, sertraline augmenting continuous low dose temozolomide. Oncotarget. 2014;5(18):8052-8082.

7. Chebouti I, Kasimir-Bauer S, Buderath P, et al. EMT-like circulating tumor cells in ovarian cancer patients are enriched by platinumbased chemotherapy. Oncotarget. Epub 2017 Mar 14. doi: 10.18632/ oncotarget.16179.

8. Jin X, Jiang YZ, Chen S, Yu KD, Shao ZM, Di GH. Prognostic value of receptor conversion after neoadjuvant chemotherapy in breast cancer patients: a prospective observational study. Oncotarget. 2015;6(11):9600-9611.

9. Toss A, Venturelli M, Peterle C, Piacentini F, Cascinu S, Cortesi L. Molecular biomarkers for prediction of targeted therapy response in metastatic breast cancer: trick or treat? Int J Mol Sci. 2017;18(1):E85. doi: 10.3390/ijms 18010085 .

10. Sambi M, Haq S, Samuel V, et al. Alternative therapies for metastatic breast cancer: multimodal approach targeting tumor cell heterogeneity. Breast Cancer (Dove Med Press). 2017;9:85-93.

11. Jonsson VD, Blakely CM, Lin L, et al. Novel computational method for predicting polytherapy switching strategies to overcome tumor heterogeneity and evolution. Sci Rep. 2017;7:44206.
12. Blakely $\mathrm{CM}$, Watkins TBK, Wu W, et al. Evolution and clinical impact of genetic epistasis within EGFR-mutant lung cancers. bioRxiv. 2017. Available from: http://biorxiv.org/content/biorxiv/ early/2017/03/16/117291.full.pdf. Accessed March 16, 2017.

13. Yeung KT, Yang J. Epithelial-mesenchymal transition in tumor metastasis. Mol Oncol. 2017;11(1):28-39.

14. Creighton CJ, Gibbons DL, Kurie JM. The role of epithelialmesenchymal transition programming in invasion and metastasis: a clinical perspective. Cancer Manag Res. 2013;5:187-195.

15. Wu Y, Sarkissyan M, Vadgama JV. Epithelial-mesenchymal transition and breast cancer. J Clin Med. 2016;5(2):E13.

16. Mock K, Preca BT, Brummer T, Brabletz S, Stemmler MP, Brabletz T. The EMT-activator ZEB1 induces bone metastasis associated genes including BMP-inhibitors. Oncotarget. 2015;6(16):14399-14412.

17. Preca BT, Bajdak K, Mock K, et al. A novel ZEB1/HAS2 positive feedback loop promotes EMT in breast cancer. Oncotarget. 2017;8(7):11530-11543.

18. Tan EJ, Olsson AK, Moustakas A. Reprogramming during epithelial to mesenchymal transition under the control of TGF $\beta$. Cell Adh Migr. 2015;9(3):233-246.

19. Sato R, Semba T, Saya H, Arima Y. Concise review: stem cells and epithelial-mesenchymal transition in cancer: biological implications and therapeutic targets. Stem Cells. 2016;34(8):1997-2007.

20. Chaffer CL, San Juan BP, Lim E, Weinberg RA. EMT, cell plasticity and metastasis. Cancer Metastasis Rev. 2016;35(4):645-654.

21. Yeung SF, Tong JH, Law PP, et al. Profiling of oncogenic driver events in lung adenocarcinoma revealed MET mutation as independent prognostic factor. J Thorac Oncol. 2015;10(9):1292-1300.

22. Lee Y, Jung WH, Koo JS. Adipocytes can induce epithelialmesenchymal transition in breast cancer cells. Breast Cancer Res Treat. 2015;153(2):323-335.

23. Ingthorsson S, Briem E, Bergthorsson JT, Gudjonsson T. Epithelial plasticity during human breast morphogenesis and cancer progression. J Mammary Gland Biol Neoplasia. 2016;21(3-4):139-148.

24. Bulfoni M, Gerratana L, Del Ben F, et al. In patients with metastatic breast cancer the identification of circulating tumor cells in epithelialto-mesenchymal transition is associated with a poor prognosis. Breast Cancer Res. 2016;18(1):30.

25. Bae YK, Choi JE, Kang SH, Lee SJ. Epithelial-mesenchymal transition phenotype is associated with clinicopathological factors that indicate aggressive biological behavior and poor clinical outcomes in invasive breast cancer. J Breast Cancer. 2015;18(3):256-263.

26. Jin MS, Hyun CL, Park IA, et al. SIRT1 induces tumor invasion by targeting epithelial mesenchymal transition-related pathway and is a prognostic marker in triple negative breast cancer. Tumour Biol. 2016;37(4):4743-4753.

27. Kotiyal S, Bhattacharya S. Epithelial mesenchymal transition and vascular mimicry in breast cancer stem cells. Crit Rev Eukaryot Gene Expr. 2015;25(3):269-280.

28. Wu ZH, Tao ZH, Zhang J, et al. MiRNA-21 induces epithelial to mesenchymal transition and gemcitabine resistance via the PTEN/AKT pathway in breast cancer. Tumour Biol. 2016;37(6): 7245-7254.

29. Scimeca M, Antonacci C, Colombo D, Bonfiglio R, Buonomo OC, Bonanno E. Emerging prognostic markers related to mesenchymal characteristics of poorly differentiated breast cancers. Tumour Biol. 2016;37(4):5427-5435.

30. Bhowmik SK, Ramirez-Pena E, Arnold JM, et al. EMT-induced metabolite signature identifies poor clinical outcome. Oncotarget. 2015;6(40):42651-42660.

31. Fernandez-Garcia B, Eiro N, Marin L, et al. Expression and prognostic significance of fibronectin and matrix metalloproteases in breast cancer metastasis. Histopathology. 2014;64:512-522.

32. Zhou X, Zhang J, Yun H, et al. Alterations of biomarker profiles after neoadjuvant chemotherapy in breast cancer: tumor heterogeneity should be taken into consideration. Oncotarget. 2015;6(34): 36894-36902. 
33. Park SY, Kim MJ, Park SA, et al. Combinatorial TGF-beta attenuation with paclitaxel inhibits the epithelial-to-mesenchymal transition and breast cancer stem-like cells. Oncotarget. 2015;6(35):37526-37543.

34. Choi HS, Cho SG, Kim MK, et al. SH003 enhances paclitaxel chemosensitivity in MCF-7/PAX breast cancer cells through inhibition of MDR1 activity. Mol Cell Biochem. 2017;426(1-2):1-8.

35. Xu J, Liu D, Niu H, et al. Resveratrol reverses doxorubicin resistance by inhibiting epithelial-mesenchymal transition (EMT) through modulating PTEN/Akt signaling pathway in gastric cancer. J Exp Clin Cancer Res. 2017;36(1):19.

36. Yoshimasu T, Ohashi T, Oura S, et al. A theoretical model for the hormetic dose-response curve for anticancer agents. Anticancer Res. 2015;35(11):5851-5855.

37. Mathenge EG, Dean CA, Clements D, et al. Core needle biopsy of breast cancer tumors increases distant metastases in a mouse model. Neoplasia. 2014;16(11):950-960.

38. Szalayova G, Ogrodnik A, Spencer B, et al. Human breast cancer biopsies induce eosinophil recruitment and enhance adjacent cancer cell proliferation. Breast Cancer Res Treat. 2016;157(3):461-474.

39. Juratli MA, Siegel ER, Nedosekin DA, et al. In vivo long-term monitoring of circulating tumor cells fluctuation during medical interventions. PLoS One. 2015;10(9):e0137613.

40. Kaigorodova EV, Tarabanovskaya NA, Staheeva MN, et al. Effect of small and radical surgical injury on the level of different populations of circulating tumor cells in the blood of breast cancer patients. Neoplasma. 2017;64(3):437-443. doi: 10.4149/neo_2017_315.

41. Tsumura H, Satoh T, Ishiyama $H$, et al. Perioperative search for circulating tumor cells in patients undergoing prostate brachytherapy for clinically nonmetastatic prostate cancer. Int J Mol Sci. 2017;18(1):E128.

42. Hara N, Kasahara T, Kawasaki T, et al. Frequency of PSA-mRNAbearing cells in the peripheral blood of patients after prostate biopsy. Br J Cancer. 2001;85(4):557-562.

43. Dyavanagoudar S, Kale A, Bhat K, Hallikerimath S. Reverse transcriptase polymerase chain reaction study to evaluate dissemination of cancer cells into circulation after incision biopsy in oral squamous cell carcinoma. Indian J Dent Res. 2008;19(4):315-319.

44. Kusukawa J, Suefuji Y, Ryu F, Noguchi R, Iwamoto O, Kameyama T. Dissemination of cancer cells into circulation occurs by incisional biopsy of oral squamous cell carcinoma. J Oral Pathol Med. 2000;29(7):303-307.

45. Moncharmont C, Levy A, Guy JB, et al. Radiation-enhanced cell migration/invasion process: a review. Crit Rev Oncol Hematol. 2014;92(2):133-142.

46. Lee HM, Hwang KA, Choi KC. Diverse pathways of epithelial mesenchymal transition related with cancer progression and metastasis and potential effects of endocrine disrupting chemicals on epithelial mesenchymal transition process. Mol Cell Endocrinol. Epub 2016 Dec 29.

47. Kast RE, Hill QA, Wion D, et al. Glioblastoma-synthesized G-CSF and GM-CSF contribute to growth and immunosuppression: potential therapeutic benefit from dapsone, fenofibrate, and ribavirin. Tumour Biol. 2017;39(5):1010428317699797. doi: 10.1177/1010428317699797.

48. Leyland-Jones B, Bondarenko I, Nemsadze G, et al. A randomized, open-label, multicenter, phase III study of epoetin alfa versus best standard of care in anemic patients with metastatic breast cancer receiving standard chemotherapy. J Clin Oncol. 2016;34(11):1197-1207.

49. Vilalta M, Rafat M, Giaccia AJ, Graves EE. Recruitment of circulating breast cancer cells is stimulated by radiotherapy. Cell Rep. 2014;8(2):402-409.

50. Kim RK, Kaushik N, Suh Y, et al. Radiation driven epithelialmesenchymal transition is mediated by Notch signaling in breast cancer. Oncotarget. 2016;7(33):53430-53442.

51. Lee SY, Jeong EK, Ju MK, et al. Induction of metastasis, cancer stem cell phenotype, and oncogenic metabolism in cancer cells by ionizing radiation. Mol Cancer. 2017;16(1):10.
52. Zhao R, Cai Z, Li S, et al. Expression and clinical relevance of epithelial and mesenchymal markers in circulating tumor cells from colorectal cancer. Oncotarget. 2017;8(6):9293-9302.

53. Zheng X, Fan L, Zhou P, et al. Detection of circulating tumor cells and circulating tumor microemboli in gastric cancer. Transl Oncol. 2017;10(3):431-441.

54. Zhang D, Zhao L, Zhou $\mathrm{P}$, et al. Circulating tumor microemboli (CTM) and vimentin + circulating tumor cells (CTCs) detected by a size-based platform predict worse prognosis in advanced colorectal cancer patients during chemotherapy. Cancer Cell Int. 2017;17:6.

55. Kolbl AC, Jeschke U, Andergassen U. The significance of epithelialto-mesenchymal transition for circulating tumor cells. Int J Mol Sci. 2016;17(8):E1308.

56. Kiesel L, Kohl A. Role of the RANK/RANKL pathway in breast cancer. Maturitas. 2016;86:10-16.

57. Wang H, Shen W, Hu X, et al. Quetiapine inhibits osteoclastogenesis and prevents human breast cancer-induced bone loss through suppression of the RANKL-mediated MAPK and NF- $\kappa B$ signaling pathways. Breast Cancer Res Treat. 2015;149(3):705-714.

58. Palafox M, Ferrer I, Pellegrini P, et al. RANK induces epithelialmesenchymal transition and stemness in human mammary epithelial cells and promotes tumorigenesis and metastasis. Cancer Res. 2012;72(11):2879-2888.

59. Beleut M, Rajaram RD, Caikovski M, et al. Two distinct mechanisms underlie progesterone-induced proliferation in the mammary gland. Proc Natl Acad Sci U S A. 2010;107(7):2989-2994.

60. Kan C, Vargas G, Pape FL, Clézardin P. Cancer cell colonisation in the bone microenvironment. Int J Mol Sci. 2016;17(10):E1674.

61. Yoneda T, Tanaka S, Hata K. Role of RANKL/RANK in primary and secondary breast cancer. World J Orthop. 2013;4(4):178-185.

62. Futakuchi M, Fukamachi K, Suzui M. Heterogeneity of tumor cells in the bone microenvironment: mechanisms and therapeutic targets for bone metastasis of prostate or breast cancer. Adv Drug Deliv Rev. 2016;99(pt B):206-211.

63. Lamora A, Talbot J, Mullard M, Brounais-Le Royer B, Redini F, Verrecchia F. TGF- $\beta$ signaling in bone remodeling and osteosarcoma progression. J Clin Med. 2016;5(11):E96.

64. King TE Jr, Bradford WZ, Castro-Bernardini S, et al; ASCEND Study Group. A phase 3 trial of pirfenidone in patients with idiopathic pulmonary fibrosis. N Engl J Med. 2014;370(22):2083-2092.

65. Nathan SD, Albera C, Bradford WZ, et al. Effect of continued treatment with pirfenidone following clinically meaningful declines in forced vital capacity: analysis of data from three phase 3 trials in patients with idiopathic pulmonary fibrosis. Thorax. 2016;71(5):429-435.

66. Conte E, Gili E, Fagone E, Fruciano M, Iemmolo M, Vancheri C. Effect of pirfenidone on proliferation, TGF- $\beta$-induced myofibroblast differentiation and fibrogenic activity of primary human lung fibroblasts. Eur J Pharm Sci. 2014;58:13-19.

67. Du J, Paz K, Flynn R, et al. Pirfenidone ameliorates murine chronic GVHD through inhibition of macrophage infiltration and TGF-beta production. Blood. 2017;129(18):2570-2580.

68. Stahnke T, Kowtharapu BS, Stachs O, et al. Suppression of TGF-beta pathway by pirfenidone decreases extracellular matrix deposition in ocular fibroblasts in vitro. PLoS One. 2017;12(2):e0172592.

69. Didiasova M, Singh R, Wilhelm J, et al. Pirfenidone exerts antifibrotic effects through inhibition of GLI transcription factors. FASEB J. 2017;31(5):1916-1928.

70. Yu W, Guo F, Song X. Effects and mechanisms of pirfenidone, prednisone and acetylcysteine on pulmonary fibrosis in rat idiopathic pulmonary fibrosis models. Pharm Biol. 2017;55(1):450-455.

71. Fujiwara A, Shintani Y, Funaki S, et al. Pirfenidone plays a biphasic role in inhibition of epithelial-mesenchymal transition in non-small cell lung cancer. Lung Cancer. 2017;106:8-16.

72. Cantelli G, Crosas-Molist E, Georgouli M, Sanz-Moreno V. TGFbetainduced transcription in cancer. Semin Cancer Biol. 2017;42:60-69. 
73. Lin RL, Zhao LJ. Mechanistic basis and clinical relevance of the role of transforming growth factor-beta in cancer. Cancer Biol Med. 2015;12(4):385-393.

74. Bellomo C, Caja L, Moustakas A. Transforming growth factor beta as regulator of cancer stemness and metastasis. Br J Cancer. 2016;115(7):761-769.

75. Felipe Lima J, Nofech-Mozes S, Bayani J, Bartlett JM. EMT in breast carcinoma-A review. J Clin Med. 2016;5(7):E65.

76. Li L, Qi L, Liang Z, et al. Transforming growth factor- $\beta 1$ induces EMT by the transactivation of epidermal growth factor signaling through HA/CD44 in lung and breast cancer cells. Int J Mol Med. 2015;36(1):113-122.

77. Chen W, Zhou S, Mao L, et al. Crosstalk between TGF-beta signaling and miRNAs in breast cancer metastasis. Tumour Biol. 2016;37(8):10011-10019.

78. Li Z, Liu X, Wang B, et al. Pirfenidone suppresses MAPK signaling pathway to reverse epithelial-mesenchymal transition and renal fibrosis. Nephrology (Carlton). Epub 2016 Jun 1. doi: 10.1111/nep.12831.

79. Pang MF, Georgoudaki AM, Lambut L, et al. TGF- $\beta 1$-induced EMT promotes targeted migration of breast cancer cells through the lymphatic system by the activation of CCR7/CCL21-mediated chemotaxis. Oncogene. 2016;35(6):748-760.

80. Ye Y, Liu S, Wu C, Sun Z. TGF $\beta$ modulates inflammatory cytokines and growth factors to create premetastatic microenvironment and stimulate lung metastasis. J Mol Histol. 2015;46(4-5):365-375.

81. Chen L, Fu H, Luo Y, et al. cPLA2 $\alpha$ mediates TGF- $\beta$-induced epithelial-mesenchymal transition in breast cancer through PI3k/Akt signaling. Cell Death Dis. 2017;8(4):e2728.

82. Ruff M, Leyme A, Le Cann F, et al. The disintegrin and metalloprotease ADAM12 is associated with TGF-beta-induced epithelial to mesenchymal transition. PLoS One. 2015;10(9):e0139179.

83. Desai K, Aiyappa R, Prabhu JS, et al. HR+HER2- breast cancers with growth factor receptor-mediated EMT have a poor prognosis and lapatinib downregulates EMT in MCF-7 cells. Tumour Biol. 2017;39(3):1010428317695028. doi: 10.1177/1010428317695028.

84. Nooshinfar E, Safaroghli-Azar A, Bashash D, Akbari ME. Melatonin, an inhibitory agent in breast cancer. Breast Cancer. 2017;24(1):42-51.

85. Zhou YC, Liu JY, Li J, et al. Ionizing radiation promotes migration and invasion of cancer cells through transforming growth factor-betamediated epithelial-mesenchymal transition. Int J Radiat Oncol Biol Phys. 2011;81(5):1530-1537.

86. Mediavilla-Varela M, Boateng K, Noyes D, Antonia SJ. The antifibrotic agent pirfenidone synergizes with cisplatin in killing tumor cells and cancer associated fibroblasts. BMC Cancer. 2016;16:176.

87. Choi SH, Nam JK, Jang J, Lee HJ, Lee YJ. Pirfenidone enhances the efficacy of combined radiation and sunitinib therapy. Biochem Biophys Res Commun. 2015;462(2):138-143.

88. Kozono S, Ohuchida K, Eguchi D, et al. Pirfenidone inhibits pancreatic cancer desmoplasia by regulating stellate cells. Cancer Res. 2013;73(7):2345-2356.

89. Takai K, Le A, Weaver VM, Werb Z. Targeting the cancer-associated fibroblasts as a treatment in triple-negative breast cancer. Oncotarget. 2016;7(50):82889-82901.

90. Polydorou C, Mpekris F, Papageorgis P, Voutouri C, Stylianopoulos T. Pirfenidone normalizes the tumor microenvironment to improve chemotherapy. Oncotarget. 2017;8(15):24506-24517.

91. Wang X, Wei S, Zhao Y, et al. Anti-proliferation of breast cancer cells with itraconazole: Hedgehog pathway inhibition induces apoptosis and autophagic cell death. Cancer Lett. 2017;385:128-136.

92. Flores-Contreras L, Sandoval-Rodríguez AS, Mena-Enriquez MG, et al. Treatment with pirfenidone for two years decreases fibrosis, cytokine levels and enhances CB2 gene expression in patients with chronic hepatitis C. BMC Gastroenterol. 2014;14:131.

93. Szabó R. Antiviral therapy and prevention against hantavirus infections. Acta Virol. 2017;61(1):3-12.

94. Kast RE. Ribavirin in cancer immunotherapies: controlling nitric oxide augments cytotoxic lymphocyte function. Neoplasia. 2003; $5(1): 3-8$.
95. Dixit NM, Layden-Almer JE, Layden TJ, Perelson AS. Modelling how ribavirin improves interferon response rates in hepatitis $\mathrm{C}$ virus infection. Nature. 2004;432(7019):922-924.

96. Nakatsuka K, Atsukawa M, Shimizu M, Takahashi H, Kawamoto C. Ribavirin contributes to eradicate hepatitis $\mathrm{C}$ virus through polarization of T helper $1 / 2$ cell balance into T helper 1 dominance. World $J$ Hepatol. 2015;7(25):2590-2596.

97. Siddiqui N, Sonenberg N. Signalling to eIF4E in cancer. Biochem Soc Trans. 2015;43(5):763-772.

98. Kerekatte V, Smiley K, Hu B, Smith A, Gelder F, De Benedetti A. The proto-oncogene/translation factor eIF4E: a survey of its expression in breast carcinomas. Int J Cancer. 1995;64(1):27-31.

99. Qin X, Jiang B, Zhang Y. 4E-BP1, a multifactor regulated multifunctional protein. Cell Cycle. 2016;15(6):781-786.

100. Wang R, Ganesan S, Zheng XF. Yin and yang of 4E-BP1 in cancer. Cell Cycle. 2016;15(11):1401-1402.

101. Muller D, Lasfargues C, El Khawand S, et al. 4E-BP restrains eIF4E phosphorylation. Translation (Austin). 2013;1(2):e25819.

102. Grzmil M, Huber RM, Hess D, et al. MNK1 pathway activity maintains protein synthesis in rapalog-treated gliomas. J Clin Invest. 2014;124(2):742-754.

103. Armengol G, Rojo F, Castellví J, et al. 4E-binding protein 1: a key molecular "funnel factor" in human cancer with clinical implications. Cancer Res. 2007;67(16):7551-7555.

104. Ramalingam S, Gediya L, Kwegyir-Afful AK, et al. First MNKs degrading agents block phosphorylation of eIF4E, induce apoptosis, inhibit cell growth, migration and invasion in triple negative and Her2-overexpressing breast cancer cell lines. Oncotarget. 2014;5(2):530-543.

105. Pyronnet S. Phosphorylation of the cap-binding protein eIF4E by the MAPK-activated protein kinase Mnk1. Biochem Pharmacol. 2000;60(8):1237-1243.

106. Lu C, Makala L, Wu D, Cai Y. Targeting translation: eIF4E as an emerging anticancer drug target. Expert Rev Mol Med. 2016;18:e2.

107. Fan W, Wang W, Mao X, et al. Elevated levels of p-Mnk1, p-eIF4E and p-p70S6K proteins are associated with tumor recurrence and poor prognosis in astrocytomas. $J$ Neurooncol. 2017;131(3):485-493.

108. Grzmil M, Seebacher J, Hess D, et al. Inhibition of MNK pathways enhances cancer cell response to chemotherapy with temozolomide and targeted radionuclide therapy. Cell Signal. 2016;28(9):1412-1421.

109. Li S, Fu J, Lu C, et al. Elevated translation initiation factor eIF4E is an attractive therapeutic target in multiple myeloma. Mol Cancer Ther. 2016;15(4):711-719.

110. Karaki S, Andrieu C, Ziouziou H, Rocchi P. The eukaryotic translation initiation factor 4E (eIF4E) as a therapeutic target for cancer. $A d v$ Protein Chem Struct Biol. 2015;101:1-26.

111. Hu A, Sun M, Yan D, Chen K. Clinical significance of mTOR and eIF4E expression in invasive ductal carcinoma. Tumori. 2014;100(5):541-546.

112. DeFatta RJ, Turbat-Herrera EA, Li BD, Anderson W, De Benedetti A. Elevated expression of eIF4E in confined early breast cancer lesions: possible role of hypoxia. Int J Cancer. 1999;80(4):516-522.

113. Sorrells DL, Black DR, Meschonat C, et al. Detection of eIF4E gene amplification in breast cancer by competitive PCR. Ann Surg Oncol. 1998;5(3):232-237.

114. Norton KS, McClusky D, Sen S, et al. TLK1B is elevated with eIF4E overexpression in breast cancer. J Surg Res. 2004;116(1):98-103.

115. Heikkinen T, Korpela T, Fagerholm R, et al. Eukaryotic translation initiation factor 4E (eIF4E) expression is associated with breast cancer tumor phenotype and predicts survival after anthracycline chemotherapy treatment. Breast Cancer Res Treat. 2013;141(1):79-88.

116. Ramon Y, Cajal S, De Mattos-Arruda L, Sonenberg N, Cortes J, Peg V. The intra-tumor heterogeneity of cell signaling factors in breast cancer: p4E-BP1 and peIF4E are diffusely expressed and are real potential targets. Clin Transl Oncol. 2014;16(11):937-941.

117. Li BD, Gruner JS, Abreo F, et al. Prospective study of eukaryotic initiation factor $4 \mathrm{E}$ protein elevation and breast cancer outcome. Ann Surg. 2002;235(5):732-738. 
118. McClusky DR, Chu Q, Yu H, et al. A prospective trial on initiation factor 4E (eIF4E) overexpression and cancer recurrence in node-positive breast cancer. Ann Surg. 2005;242(4):584-590.

119. Yin X, Kim RH, Sun G, Miller JK, Li BD. Overexpression of eukaryotic initiation factor $4 \mathrm{E}$ is correlated with increased risk for systemic dissemination in node positive breast cancer patients. J Am Coll Surg. 2014;218(4):663-671.

120. Li Z, Sun Y, Qu M, Wan H, Cai F, Zhang P. Inhibiting the MNK-eIF4Ebeta-catenin axis increases responsiveness of aggressive breast cancer cells to chemotherapy. Oncotarget. 2017;8(2):2906-2915.

121. Volpin F, Casaos J, Sesen J, et al. Use of an anti-viral drug, ribavirin, as an anti-glioblastoma therapeutic. Oncogene. 2017;36(21):3037-3047.

122. Bhat M, Yanagiya A, Graber T, et al. Metformin requires 4E-BPs to induce apoptosis and repress translation of Mcl-1 in hepatocellular carcinoma cells. Oncotarget. Epub 2016 Jul 18. doi: 10.18632/ oncotarget.10671.

123. Pons B, Peg V, Vázquez-Sánchez MA, et al. The effect of p-4E-BP1 and p-eIF4E on cell proliferation in a breast cancer model. Int J Oncol. 2011;39(5):1337-1345.

124. Shi F, Len Y, Gong Y, et al. Ribavirin inhibits the activity of mTOR/ eIF4E, ERK/Mnk1/eIF4E signaling pathway and synergizes with tyrosine kinase inhibitor imatinib to impair Bcr-Abl mediated proliferation and apoptosis in Ph+ leukemia. PLoS One. 2015;10(8):e0136746.

125. Zhang Y, Zheng XF. mTOR-independent 4E-BP1 phosphorylation is associated with cancer resistance to mTOR kinase inhibitors. Cell Cycle. 2012;11(3):594-603.

126. Kentsis A, Volpon L, Topisirovic I, et al. Further evidence that ribavirin interacts with eIF4E. RNA. 2005;11(12):1762-1766.

127. Kentsis A, Topisirovic I, Culjkovic B, Shao L, Borden KL. Ribavirin suppresses eIF4E-mediated oncogenic transformation by physical mimicry of the 7-methyl guanosine mRNA cap. Proc Natl Acad Sci US A. 2004;101(52):18105-18110.

128. Pettersson F, Yau C, Dobocan MC, et al. Ribavirin treatment effects on breast cancers overexpressing eIF4E, a biomarker with prognostic specificity for luminal B-type breast cancer. Clin Cancer Res. 2011;17(9):2874-2884.

129. Pettersson F, Del Rincon SV, Emond A, et al. Genetic and pharmacologic inhibition of eIF4E reduces breast cancer cell migration, invasion, and metastasis. Cancer Res. 2015;75(6):1102-1112.

130. Isakovic AM, Dulovic M, Markovic I, et al. Autophagy suppression sensitizes glioma cells to IMP dehydrogenase inhibition-induced apoptotic death. Exp Cell Res. 2017;350(1):32-40.

131. Ogino A, Sano E, Ochiai Y, et al. Efficacy of ribavirin against malignant glioma cell lines. Oncol Lett. 2014;8(6):2469-2474.

132. Criscitiello C, Gelao L, Viale G, Esposito A, Curigliano G. Investigational platelet-derived growth factor receptor kinase inhibitors in breast cancer therapy. Expert Opin Investig Drugs. 2014;23(5):599-610.

133. Yu JM, Sun W, Hua F, et al. BCL6 induces EMT by promoting the ZEB1-mediated transcription repression of E-cadherin in breast cancer cells. Cancer Lett. 2015;365(2):190-200.

134. Pinto MP, Dye WW, Jacobsen BM, Horwitz KB. Malignant stroma increases luminal breast cancer cell proliferation and angiogenesis through platelet-derived growth factor signaling. BMC Cancer. 2014;14:735.

135. Weigel MT, Banerjee S, Arnedos M, et al. Enhanced expression of the $\mathrm{PDGFR} / \mathrm{Abl}$ signaling pathway in aromatase inhibitor-resistant breast cancer. Ann Oncol. 2013;24(1):126-133.

136. Attar-Schneider O, Drucker L, Gottfried M. Migration and epithelial to mesenchymal transition of lung cancer can be targeted via translation initiation factors eIF4E and eIF4GI. Lab Invest. 2016;96(9):1004-1015.

137. Nasr Z, Robert F, Porco JA Jr, Muller WJ, Pelletier J. eIF4F suppression in breast cancer affects maintenance and progression. Oncogene. 2013;32(7):861-871.

138. Robichaud N, del Rincon SV, Huor B, et al. Phosphorylation of eIF4E promotes EMT and metastasis via translational control of SNAIL and MMP-3. Oncogene. 2015;34(16):2032-2042.
139. Cuny GD, Suebsuwong C, Ray SS. Inosine-5'-monophosphate dehydrogenase (IMPDH) inhibitors: a patent and scientific literature review. Expert Opin Ther Pat. 2017;27(6):677-690.

140. Guidicelli G, Chaigne-Delalande B, Dilhuydy MS, et al. The necrotic signal induced by mycophenolic acid overcomes apoptosis-resistance in tumor cells. PLoS One. 2009;4(5):e5493.

141. Decarlo L, Mestel C, Barcellos-Hoff MH, Schneider RJ. Eukaryotic translation initiation factor $4 \mathrm{E}$ is a feed-forward translational coactivator of transforming growth factor $\beta$ early pro-transforming events in breast epithelial cells. Mol Cell Biol. 2015;35(15):2597-2609.

142. Dai D, Chen H, Tang J, Tang Y. Inhibition of mTOR/eIF4E by anti-viral drug ribavirin effectively enhances the effects of paclitaxel in oral tongue squamous cell carcinoma. Biochem Biophys Res Commun. 2017;482(4):1259-1264

143. McHutchison JG, Gordon SC, Schiff ER, et al. Interferon alfa-2b alone or in combination with ribavirin as initial treatment for chronic hepatitis C. Hepatitis Interventional Therapy Group. $N$ Engl J Med. 1998;339(21):1485-1492.

144. Crabol Y, Catherinot E, Veziris N, Jullien V, Lortholary O. Rifabutin: where do we stand in 2016? J Antimicrob Chemother. 2016;71(7) 1759-1771.

145. Kunin CM. Antimicrobial activity of rifabutin. Clin Infect Dis. 1996;22(suppl 1):S3-S13.

146. Li J, Huang Y, Gao Y, Wu H, Dong W, Liu L. Antibiotic drug rifabutin is effective against lung cancer cells by targeting the eIF4E- $\beta$-catenin axis. Biochem Biophys Res Commun. 2016;472(2):299-305.

147. Nakayama S, Sng N, Carretero J, et al. $\beta$-catenin contributes to lung tumor development induced by EGFR mutations. Cancer Res. 2014;74(20):5891-5902.

148. Togashi $\mathrm{Y}$, Hayashi $\mathrm{H}$, Terashima $\mathrm{M}$, et al. Inhibition of $\beta$-Catenin enhances the anticancer effect of irreversible EGFR-TKI in EGFRmutated non-small-cell lung cancer with a T790M mutation. JThorac Oncol. 2015;10(1):93-101.

149. Wei Z, Gao W, Wu Y, Ni B, Tian Y. Mutual interaction between BCL6 and miRNAs contributing to the pathogenesis of various cancers. Clin Transl Oncol. 2015;17(11):841-846.

150. Wu Q, Liu X, Yan H, et al. B-cell lymphoma 6 protein stimulates oncogenicity of human breast cancer cells. BMC Cancer. 2014;14:418.

151. Walker SR, Frank DA. Targeting BCL6 and STAT3 in triple negative breast cancer: the one-two punch? Oncoscience. 2015;2(11):912.

152. Chang CC, Ye BH, Chaganti RS, Dalla-Favera R. BCL-6, a POZ/ zinc-finger protein, is a sequence-specific transcriptional repressor. Proc Natl Acad Sci U S A. 1996;93(14):6947-6952.

153. Evans SE, Goult BT, Fairall L, et al. The ansamycin antibiotic, rifamycin SV, inhibits BCL6 transcriptional repression and forms a complex with the BCL6-BTB/POZ domain. PLoS One. 2014;9(3): e90889.

154. Zhu Z, Wang S, Zhu J, Yang Q, Dong H, Huang J. MicroRNA-544 down-regulates both Bcl6 and Stat 3 to inhibit tumor growth of human triple negative breast cancer. Biol Chem. 2016;397(10):1087-1095.

155. Goodman CR, Sato T, Peck AR, et al. Steroid induction of therapyresistant cytokeratin-5-positive cells in estrogen receptor positive breast cancer through a BCL6-dependent mechanism. Oncogene. 2016;35(11):1373-1385.

156. An H, He L. Current understanding of metformin effect on the control of hyperglycemia in diabetes. J Endocrinol. 2016;228(3):R97-R106.

157. Zou YF, Xie CW, Yang SX, Xiong JP. AMPK activators suppress breast cancer cell growth by inhibiting DVL3-facilitated Wnt/beta-catenin signaling pathway activity. Mol Med Rep. 2017;15(2):899-907.

158. Xu H, Aldrich MC, Chen Q, et al. Validating drug repurposing signals using electronic health records: a case study of metformin associated with reduced cancer mortality. J Am Med Inform Assoc. 2015;22(1): 179-191.

159. Sośnicki S, Kapral M, Węglarz L. Molecular targets of metformin antitumor action. Pharmacol Rep. 2016;68(5):918-925. 
160. Gongol B, Marin T, Peng IC, et al. AMPK exerts its anti-inflammatory effects through PARP-1 and Bcl-6. Proc NatlAcad Sci USA. 2013;110(8): 3161-3166.

161. Queiroz EA, Puukila S, Eichler R, et al. Metformin induces apoptosis and cell cycle arrest mediated by oxidative stress, AMPK and FOXO3a in MCF-7 breast cancer cells. PLoS One. 2014;9(5):e98207.

162. Silvestri A, Palumbo F, Rasi I, et al. Metformin induces apoptosis and downregulates pyruvate kinase M2 in breast cancer cells only when grown in nutrient-poor conditions. PLoS One. 2015;10(8):e0136250.

163. Wu L, Zhou B, Oshiro-Rapley N, et al. An ancient, unified mechanism for metformin growth inhibition in C. elegans and cancer. Cell. 2016;167(7):1705.e13-1718.e13.

164. Ben Sahra I, Regazzetti C, Robert G, et al. Metformin, independent of AMPK, induces mTOR inhibition and cell-cycle arrest through REDD1. Cancer Res. 2011;71(13):4366-4372.

165. Gui DY, Sullivan LB, Luengo A, et al. Environment dictates dependence on mitochondrial complex I for NAD+ and aspartate production and determines cancer cell sensitivity to metformin. Cell Metab. 2016;24(5):716-727.

166. Chae YK, Arya A, Malecek MK, et al. Repurposing metformin for cancer treatment: current clinical studies. Oncotarget. 2016;7(26):40767-40780.

167. Coyle C, Cafferty FH, Vale C, Langley RE. Metformin as an adjuvant treatment for cancer: a systematic review and meta-analysis. Ann Oncol. 2016;27(12):2184-2195.

168. Gadducci A, Biglia N, Tana R, Cosio S, Gallo M. Metformin use and gynecological cancers: a novel treatment option emerging from drug repositioning. Crit Rev Oncol Hematol. 2016;105:73-83.

169. Zhang HH, Guo XL. Combinational strategies of metformin and chemotherapy in cancers. Cancer Chemother Pharmacol.2016;78(1): $13-26$.

170. Cazzaniga M, Bonanni B. Breast cancer metabolism and mitochondrial activity: the possibility of chemoprevention with metformin. Biomed Res Int. 2015;2015:972193.

171. Qu C, Zhang W, Zheng G, Zhang Z, Yin J, He Z. Metformin reverses multidrug resistance and epithelial-mesenchymal transition (EMT) via activating AMP-activated protein kinase (AMPK) in human breast cancer cells. Mol Cell Biochem. 2014;386(1-2):63-71.

172. Soo JS, Ng CH, Tan SH, et al. Metformin synergizes 5-fluorouracil, epirubicin, and cyclophosphamide (FEC) combination therapy through impairing intracellular ATP production and DNA repair in breast cancer stem cells. Apoptosis. 2015;20(10):1373-1387.

173. Honjo S, Ajani JA, Scott AW, et al. Metformin sensitizes chemotherapy by targeting cancer stem cells and the mTOR pathway in esophageal cancer. Int J Oncol. 2014;45(2):567-574.

174. Harada K, Ferdous T, Harada T, Ueyama Y. Metformin in combination with 5-fluorouracil suppresses tumor growth by inhibiting the Warburg effect in human oral squamous cell carcinoma. Int $J$ Oncol. 2016;49(1):276-284.

175. Tian Y, Tang B, Wang C, et al. Metformin mediates resensitivity to 5 -fluorouracil in hepatocellular carcinoma via the suppression of YAP. Oncotarget. 2016;7(29):46230-46241.

176. Engels CC, de Glas NA, Sajet A, et al. The influence of insulin-like Growth Factor-1 Receptor expression and endocrine treatment on clinical outcome of postmenopausal hormone receptor positive breast cancer patients: a Dutch TEAM substudy analysis. Mol Oncol. 2016;10(4):509-516.

177. Hadad S, Iwamoto T, Jordan L, et al. Evidence for biological effects of metformin in operable breast cancer: a pre-operative, window-of-opportunity, randomized trial. Breast Cancer Res Treat. 2011;128(3):783-794.

178. Niraula S, Dowling RO, Ennis M, et al. Metformin in early breast cancer: a prospective window of opportunity neoadjuvant study. Breast Cancer Res Treat. 2012;135(3):821-830.

179. Kalinsky K, Crew KD, Refice S, et al. Presurgical trial of metformin in overweight and obese patients with newly diagnosed breast cancer. Cancer Invest. 2014;32(4):150-157.
180. Bonanni B, Puntoni M, Cazzaniga M, et al. Dual effect of metformin on breast cancer proliferation in a randomized presurgical trial. J Clin Oncol. 2012;30(21):2593-2600.

181. Cabello P, Pineda B, Tormo E, Lluch A, Eroles P. The antitumor effect of metformin is mediated by miR-26a in breast cancer. Int $J \mathrm{Mol} \mathrm{Sci}$. 2016;17(8):E1298.

182. Labuzek K, Suchy D, Gabryel B, Bielecka A, Liber S, Okopień B. Quantification of metformin by the HPLC method in brain regions, cerebrospinal fluid and plasma of rats treated with lipopolysaccharide. Pharmacol Rep. 2010;62(5):956-965.

183. Lalau JD, Lemaire-Hurtel AS, Lacroix C. Establishment of a database of metformin plasma concentrations and erythrocyte levels in normal and emergency situations. Clin Drug Investig. 2011;31(6):435-438.

184. Pantziarka P, Bouche G, Sukhatme V, Meheus L, Rooman I, Sukhatme VP. Repurposing drugs in oncology (ReDO)-propranolol as an anticancer agent. Ecancermedicalscience. 2016;10:680.

185. Montoya A, Amaya CN, Belmont A, et al. Use of non-selective betablockers is associated with decreased tumor proliferative indices in early stage breast cancer. Oncotarget. 2017;8(4):6446-6460.

186. Cardwell CR, Pottegård A, Vaes E, et al. Propranolol and survival from breast cancer: a pooled analysis of European breast cancer cohorts. Breast Cancer Res. 2016;18(1):119.

187. Rico M, Baglioni M, Bondarenko M, et al. Metformin and propranolol combination prevents cancer progression and metastasis in different breast cancer models. Oncotarget. 2017;8(2):2874-2889.

188. Botteri E, Munzone E, Rotmensz N, et al. Therapeutic effect of $\beta$-blockers in triple-negative breast cancer postmenopausal women. Breast Cancer Res Treat. 2013;140(3):567-575.

189. Hwa YL, Shi Q, Kumar SK, et al. Beta-blockers improve survival outcomes in patients with multiple myeloma: a retrospective evaluation. Am J Hematol. 2017;92(1):50-55.

190. Choy C, Raytis JL, Smith DD, et al. Inhibition of $\beta 2$-adrenergic receptor reduces triple-negative breast cancer brain metastases: the potential benefit of perioperative $\beta$-blockade. Oncol Rep. 2016;35(6): 3135-3142.

191. Childers WK, Hollenbeak CS, Cheriyath P. $\beta$-blockers reduce breast cancer recurrence and breast cancer death: a meta-analysis. Clin Breast Cancer. 2015;15(6):426-431.

192. Melhem-Bertrandt A, Chavez-Macgregor M, Lei X, et al. Beta-blocker use is associated with improved relapse-free survival in patients with triple-negative breast cancer. J Clin Oncol. 2011;29(19):2645-2652.

193. Elefteriou F. Role of sympathetic nerves in the establishment of metastatic breast cancer cells in bone. J Bone Oncol. 2016;5(3): $132-134$.

194. Jang HI, Lim SH, Lee YY, et al. Perioperative administration of propranolol to women undergoing ovarian cancer surgery: a pilot study. Obstet Gynecol Sci. 2017;60(2):170-177.

195. Wang T, Li Y, Lu HL, Meng QW, Cai L, Chen XS. $\beta$-Adrenergic receptors: new target in breast cancer. Asian Pac J Cancer Prev. 2015;16(18):8031-8039.

196. Wilson JM, Lorimer E, Tyburski MD, Williams CL. $\beta$-Adrenergic receptor suppress Rap1B prenylation and promote the metastatic phenotype in breast cancer cells. Cancer Biol Ther. 2015;16(9): 1364-1374.

197. Işeri OD, Sahin FI, Terzi YK, Yurtcu E, Erdem SR, Sarialioglu F. betaAdrenoreceptor antagonists reduce cancer cell proliferation, invasion, and migration. Pharm Biol. 2014;52(11):1374-1381.

198. Kang F, Ma W, Ma X, et al. Propranolol inhibits glucose metabolism and $18 \mathrm{~F}-\mathrm{FDG}$ uptake of breast cancer through posttranscriptional downregulation of hexokinase-2. J Nucl Med. 2014;55(3):439-445.

199. Campbell JP, Karolak MR, Ma Y, et al. Stimulation of host bone marrow stromal cells by sympathetic nerves promotes breast cancer bone metastasis in mice. PLoS Biol. 2012;10(7):e1001363.

200. Sloan EK, Priceman SJ, Cox BF, et al. The sympathetic nervous system induces a metastatic switch in primary breast cancer. Cancer Res. 2010;70(18):7042-7052. 
201. Shaashua L, Shabat-Simon M, Haldar R, et al. Perioperative COX-2 and $\&$ beta-adrenergic blockade improves metastatic biomarkers in breast cancer patients in a phase-II randomized trial. Clin Cancer Res. Epub 2017 May 10. doi: 10.1158/1078-0432.CCR-17-0152.

202. Wagstaff AJ, Ibbotson T, Goa KL. Capecitabine: a review of its pharmacology and therapeutic efficacy in the management of advanced breast cancer. Drugs. 2003;63(2):217-236.

203. Walko CM, Lindley C. Capecitabine: a review. Clin Ther. 2005;27(1):23-44.

204. Daniele G, Gallo M, Piccirillo MC, et al. Pharmacokinetic evaluation of capecitabine in breast cancer. Expert Opin Drug Metab Toxicol. 2013;9(2):225-235

205. Rossi D, Alessandroni P, Catalano V, et al. Safety profile and activity of lower capecitabine dose in patients with metastatic breast cancer Clin Breast Cancer. 2007;7(11):857-860.

206. Zielinski C, Gralow J, Martin M. Optimising the dose of capecitabine in metastatic breast cancer: confused, clarified or confirmed? Ann Oncol. 2010;21(11):2145-2152.

207. Ambros T, Zeichner SB, Zaravinos J, et al. A retrospective study evaluating a fixed low dose capecitabine monotherapy in women with HER-2 negative metastatic breast cancer. Breast Cancer Res Treat. 2014;146(1):7-14.

208. Nishijima TF, Suzuki M, Muss HB. A comparison of toxicity profiles between the lower and standard dose capecitabine in breast cancer: a systematic review and meta-analysis. Breast Cancer Res Treat. 2016;156(2):227-236.

209. Azuma Y, Hata K, Sai K, et al. Significant association between handfoot syndrome and efficacy of capecitabine in patients with metastatic breast cancer. Biol Pharm Bull. 2012;35(5):717-724

210. Kast RE. Erlotinib augmentation with dapsone for rash mitigation and increased anti-cancer effectiveness. Springerplus. 2015;4:638.

211. Harbeck N, Saupe S, Jäger E, et al; PELICAN Investigators. A randomized phase III study evaluating pegylated liposomal doxorubicin versus capecitabine as first-line therapy for metastatic breast cancer: results of the PELICAN study. Breast Cancer Res Treat. 2017;161(1):63-72.

212. Emet M, Ozcan H, Ozel L, Yayla M, Halici Z, Hacimuftuoglu A. A review of melatonin, its receptors and drugs. Eurasian $\mathrm{J} \mathrm{Med}$. 2016;48(2):135-141.

213. Kast RE. Agomelatine or ramelteon as treatment adjuncts in glioblastoma and other M1 - or M2-expressing cancers. Contemp Oncol (Pozn). 2015;19(2):157-162.

214. Liu J, Clough SJ, Hutchinson AJ, Adamah-Biassi EB, Popovska-Gorevski M, Dubocovich ML. MT1 and MT2 melatonin receptors: a therapeutic perspective. Annu Rev Pharmacol Toxicol. 2016;56:361-383.

215. Hardeland R, Poeggeler B. Melatonin and synthetic melatonergic agonists: actions and metabolism in the central nervous system. Cent Nerv Syst Agents Med Chem. 2012;12(3):189-216.

216. Perlemuter G, Cacoub P, Valla D, et al. Characterisation of agomelatineinduced increase in liver enzymes: frequency and risk factors determined from a pooled analysis of 7605 treated patients. CNS Drugs. 2016;30(9):877-888.

217. Vriend J, Reiter RJ. Breast cancer cells: modulation by melatonin and the ubiquitin-proteasome system - a review. Mol Cell Endocrinol. 2015;417:1-9.

218. Hill SM, Belancio VP, Dauchy RT, et al. Melatonin: an inhibitor of breast cancer. Endocr Relat Cancer. 2015;22(3):R183-R204.

219. Cos S, Alvarez-García V, González A, Alonso-González C, MartínezCampa C. Melatonin modulation of crosstalk among malignant epithelial, endothelial and adipose cells in breast cancer. Oncol Lett. 2014;8:487-492.

220. Sánchez-Barceló EJ, Cos S, Mediavilla D, Martínez-Campa C, González A, Alonso-González C. Melatonin-estrogen interactions in breast cancer. J Pineal Res. 2005;38(4):217-222.

221. Mediavilla MD, Sánchez-Barceló EJ, Tan DX, Manchester L, Reiter RJ. Basic mechanisms involved in the anti-cancer effects of melatonin. Curr Med Chem. 2010;17:4462-4481.
222. Lopes J, Arnosti D, Trosko JE, Tai MH, Zuccari D. Melatonin decreases estrogen receptor binding to estrogen response elements sites on the OCT4 gene in human breast cancer stem cells. Genes Cancer. 2016;7(5-6):209-217.

223. Nooshinfar E, Bashash D, Safaroghli-Azar A, et al. Melatonin promotes ATO-induced apoptosis in MCF-7 cells: proposing novel therapeutic potential for breast cancer. Biomed Pharmacother. 2016;83:456-465.

224. Lopes JR, da Silva Kavagutti M, Medeiros FA, De Campos Zuccari DA. Evaluation of melatonin effect on human breast cancer stem cells using a three-dimensional growth method of mammospheres. Anticancer Agents Med Chem. Epub 2016 Sep 22.

225. Cos S, Fernández R, Güezmes A, Sánchez-Barceló EJ. Influence of melatonin on invasive and metastatic properties of MCF-7 human breast cancer cells. Cancer Res. 1998;58(19):4383-4390.

226. Mao L, Summers W, Xiang S, et al. Melatonin represses metastasis in Her2-positive human breast cancer cells by suppressing RSK2 expression. Mol Cancer Res. 2016;14(11):1159-1169.

227. Mao L, Yuan L, Slakey LM, Jones FE, Burow ME, Hill SM. Inhibition of breast cancer cell invasion by melatonin is mediated through regulation of the p38 mitogen-activated protein kinase signaling pathway. Breast Cancer Res. 2010;12(6):R107.

228. Jardim-Perassi BV, Arbab AS, Ferreira LC, et al. Effect of melatonin on tumor growth and angiogenesis in xenograft model of breast cancer. PLoS One. 2014;9(1):e85311.

229. Su SC, Hsieh MJ, Yang WE, Chung WH, Reiter RJ, Yang SF. Cancer metastasis: mechanisms of inhibition by melatonin. J Pineal Res. 2017;62(1). doi: 10.1111/jpi.12370.

230. Gonçalves Ndo N, Colombo J, Lopes JR, et al. Effect of melatonin in epithelial mesenchymal transition markers and invasive properties of breast cancer stem cells of canine and human cell lines. PLoS One. 2016;11(3):e0150407.

231. Rudra DS, Pal U, Maiti NC, Reiter RJ, Swarnakar S. Melatonin inhibits matrix metalloproteinase- 9 activity by binding to its active site. J Pineal Res. 2013;54(4):398-405.

232. Borin TF, Arbab AS, Gelaleti GB, et al. Melatonin decreases breast cancer metastasis by modulating Rho-associated kinase protein-1 expression. J Pineal Res. 2016;60(1):3-15.

233. Alvarez-Garcia V, Gonzalez A, Martinez-Campa C, Alonso-Gonzalez $\mathrm{C}, \mathrm{Cos} \mathrm{S}$. Melatonin modulates aromatase activity and expression in endothelial cells. Oncol Rep. 2013;29(5):2058-2064.

234. Alvarez-Garcia V, Gonzalez A, Alonso-Gonzalez C, Martinez-Campa C, Cos S. Antiangiogenic effects of melatonin in endothelial cell cultures. Microvasc Res. 2013;87:25-33.

235. Cos S, Alvarez-Garcia V, Gonzalez A, Alonso-Gonzalez C, MartinezCampa C. Melatonin modulation of crosstalk among malignant epithelial, endothelial and adipose cells in breast cancer (Review). Oncol Lett. 2014;8(2):487-492.

236. Wang J, Xiao X, Zhang Y, et al. Simultaneous modulation of COX-2, p300, Akt, and Apaf-1 signaling by melatonin to inhibit proliferation and induce apoptosis in breast cancer cells. J Pineal Res. 2012;53(1):77-90.

237. Martínez-Campa C, Menéndez-Menéndez J, Alonso-González C, González A, Alvarez-García V, Cos S. What is known about melatonin, chemotherapy and altered gene expression in breast cancer. Oncol Lett. 2017;13(4):2003-2014.

238. Ma C, Li LX, Zhang Y, et al. Protective and sensitive effects of melatonin combined with adriamycin on ER+ (estrogen receptor) breast cancer. Eur J Gynaecol Oncol. 2015;36(2):197-202.

239. Gao Y, Xiao X, Zhang C, et al. Melatonin synergizes the chemotherapeutic effect of 5-fluorouracil in colon cancer by suppressing PI3K/

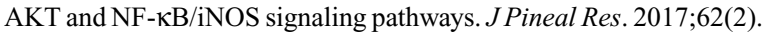
doi: 10.1111/jpi.12380.

240. Pariente R, Pariente JA, Rodríguez AB, Espino J. Melatonin sensitizes human cervical cancer HeLa cells to cisplatin-induced cytotoxicity and apoptosis: effects on oxidative stress and DNA fragmentation. $J$ Pineal Res. 2016;60(1):55-64. 
241. Uguz AC, Cig B, Espino J, et al. Melatonin potentiates chemotherapyinduced cytotoxicity and apoptosis in rat pancreatic tumor cells. J Pineal Res. 2012;53(1):91-98.

242. Ruiz-Rabelo J, Vázquez R, Arjona A, et al. Improvement of capecitabine antitumoral activity by melatonin in pancreatic cancer. Pancreas. 2011;40(3):410-414.

243. Zhelev Z, Ivanova D, Bakalova R, Aoki I, Higashi T. Synergistic cytotoxicity of melatonin and new-generation anticancer drugs against leukemia lymphocytes but not normal lymphocytes. Anticancer Res. 2017;37(1):149-159.

244. Alonso-González C, González A, Martínez-Campa C, et al. Melatonin enhancement of the radiosensitivity of human breast cancer cells is associated with the modulation of proteins involved in estrogen biosynthesis. Cancer Lett. 2016;370(1):145-152.
245. Lu JJ, Fu L, Tang Z, et al. Melatonin inhibits AP-2beta/hTERT, $\mathrm{NF}-\mathrm{kB} / \mathrm{COX}-2$ and Akt/ERK and activates caspase/Cyto $\mathrm{C}$ signaling to enhance the antitumor activity of berberine in lung cancer cells. Oncotarget. 2016;7(3):2985-3001.

246. Calvo JR, González-Yanes C, Maldonado MD. The role of melatonin in the cells of the innate immunity: a review. J Pineal Res. 2013;55(2): 103-120.

247. Devore EE, Warner ET, Eliassen AH, et al. Urinary melatonin in relation to postmenopausal breast cancer risk according to melatonin 1 receptor status. Cancer Epidemiol Biomarkers Prev. 2017;26(3):413-419.

248. Basler M, Jetter A, Fink D, Seifert B, Kullak-Ublick GA, Trojan A. Urinary excretion of melatonin and association with breast cancer: meta-analysis and review of the literature. Breast Care (Basel). 2014;9(3):182-187.

\section{Publish your work in this journal}

Breast Cancer - Targets and Therapy is an international, peerreviewed open access journal focusing on breast cancer research, identification of therapeutic targets and the optimal use of preventative and integrated treatment interventions to achieve improved outcomes, enhanced survival and quality of life for the cancer patient.
The manuscript management system is completely online and includes a very quick and fair peer-review system, which is all easy to use. Visit http://www.dovepress.com/testimonials.php to read real quotes from published authors.

Submit your manuscript here: https://www.dovepress.com/breast-cancer---targets-and-therapy-journal 